\title{
El diapirismo argilocinético del Margen Caribeño Colombiano: una revisión de sus condicionantes sedimentarios aplicados a la exploración de hidrocarburos
}

\author{
Eduardo Antonio Rossello ${ }^{1 *}\left[\right.$; Jairo Alonso Osorio $^{2}$ [D ; Sergio López-Isaza $^{3}$
}

Forma de citar: Rossello, E.A.; Osorio, J.A.; López-Isaza, S. (2022). El diapirismo argilocinético del Margen Caribeño Colombiano: una revisión de sus condicionantes sedimentarios aplicados a la exploración de hidrocarburos. Boletín de Geología, 44(1), 15-48. https://doi.org/10.18273/revbol.v44n1-2022001

\begin{abstract}
Resumen
Se analizan la morfología y evolución de los diapiros y volcanes de lodo en el Margen Caribeño Colombiano (MCC), emplazados en secuencias sedimentarias transgresivas del Cretácico al Neógeno. Son estructuras extrusivas por argilocinesis que muestran la liberación de sedimentos sobrepresionados y fluidizados por aguas y/o hidrocarburos que intruyen hasta la superficie. A partir de la modelación analógica, se concluye que los condicionantes del origen y geometría de los mecanismos del diapirismo dependen de: i) la menor densidad de los niveles generadores infrayacentes en comparación con las secuencias suprayacentes y ii) de las débiles tasas de sedimentación de las secuencias que los post-datan. La exhumación progresiva del Cinturón Sinú-San Jacinto a partir del Oligo-Mioceno, debido a la convergencia tectónica transpresiva dextral entre las placas Sudamérica y Caribe, generó una barrera al transporte sedimentario hacia el norte del paleo río Cauca. Esta interrupción impidió su descarga directa, forzándolo a coalescer hacia el río Magdalena. Se propone un provincialismo del diapirismo a partir de las diferencias en las tasas de progradación de sedimentos más densos sobre secuencias pelíticas asociadas con conspicuos tipos de plegamientos intensos: a) al norte (Cinturón San Jacinto), compresional tangencial con ejes de pliegues doblemente buzantes y escalonados subparalelamente al litoral Caribe y b) al sur (Cinturón Sinú), gravitatorio con amplios sinclinales en forma de cubetas y anticlinales estrechos. El mejor conocimiento de la evolución 4D del diapirismo en el MCC contribuye en la definición del potencial de los sistemas petroleros infrayacentes y en la prevención de riesgos ambientales en las maniobras exploratorias.
\end{abstract}

Palabras claves: Diapirismo de lodo; Tectosedimentación; Cretácico-Neógeno; Sistemas petroleros; Riesgos ambientales, Colombia.

\section{The argilokinetic diapirism of the Colombian Caribbean Margin: a review of its sedimentary conditioning factors applied to hydrocarbon exploration}

\begin{abstract}
The morphology and evolution of diapirs and mud volcanoes in the Colombian Caribbean Margin (MCC) located in transgressive Cretaceous to Neogene sedimentary sequences are analyzed in this paper. They are extrusive structures by argilokinesis that show the release of overpressure and fluidized sediments by water and/or hydrocarbons that pierce the surface. From the analogical modeling of the determining factors of origin and geometry, the diapirism mechanisms depend on: i) the lower density of the underlying generating levels compared to the overlying sequences, and ii) the weak sedimentation rates of the overlayered sequences. The progressive exhumation of the Sinú-San Jacinto Belt from the Oligo-Miocene period due to the dextral transpressive tectonic convergence between the South American and Caribbean plates, generated a barrier to sedimentary transport to the North of the Paleo Cauca River. This interruption prevented its direct discharge, forcing it to coalesce into the Magdalena River, increasing the volume of its delta. A provincialism of diapirism is proposed based on the differences in rates and chronologies of the progradation of denser sediments on pelitic sequences associated with conspicuous types of folds: a) to the north (San Jacinto Belt), tangential compressional type with a double plunge, and oriented subparallel to the Caribbean coast, and b) to the south (Sinú Belt), gravitational type with wide synclines and tight anticlines. Better knowledge of the 4D evolution of MCC diapirism contributes to the potential of the underlying oil systems and the prevention of environmental risks in exploratory maneuvers.
\end{abstract}

Keywords: Mud diapirism; Tectosedimentation; Cretaceous-Neogene; Petroleum systems; Environmental risks; Colombia.

\footnotetext{
${ }^{1}$ Consejo Nacional de Investigaciones Científicas y Técnicas - Instituto de Geología y Ciencias Básicas de Buenos Aires, Facultad de Ciencias Exactas y Naturales, Universidad de Buenos Aires, Buenos Aires, Argentina. ea_rossello@yahoo.com.ar ${ }^{2}$ Servicio Geológico Colombiano. Bogotá, Colombia. josorio@sgc.gov.co

${ }^{3}$ Facultad de Ciencias Exactas y Naturales, Universidad de Buenos Aires, Buenos Aires, Argentina. seadlois@gmail.com
} 


\section{Introducción}

El Margen Caribeño Colombiano (MCC) constituye el sector ribereño septentrional, tanto costa afuera como adentro de Colombia, que se extiende entre el Golfo de Urabá y la Península de la Guajira (Figura 1). La región comprendida al sur de Santa Marta posee una gran cantidad de evidencias de argilocinesis, que se expresan en la superficie como volcanes y emanaderos de lodo y en el subsuelo identificados como diapirismo a partir de la interpretación sísmica relacionada con las actividades exploratorias por hidrocarburos (Shepard et al., 1968; Duque-Caro, 1984a, 1984b; Vernette, 1989; Toto y Kellogg, 1992; Vernette et al., 1992; Briceño y Vernette, 1992; Guzmán et al., 2004; Carvajal et al., 2010; Carvajal y Mendivelso, 2017; Herrera-Atencio y Díaz-Mendoza, 2018; García-González et al., 2019; Rodríguez et al., 2021). Con la finalidad de contextualizar el ambiente tectosedimentario del MCC, se sintetizan las principales características petrológicas y depositacionales de las secuencias sedimentarias relacionadas con el origen y emplazamiento del diapirismo.

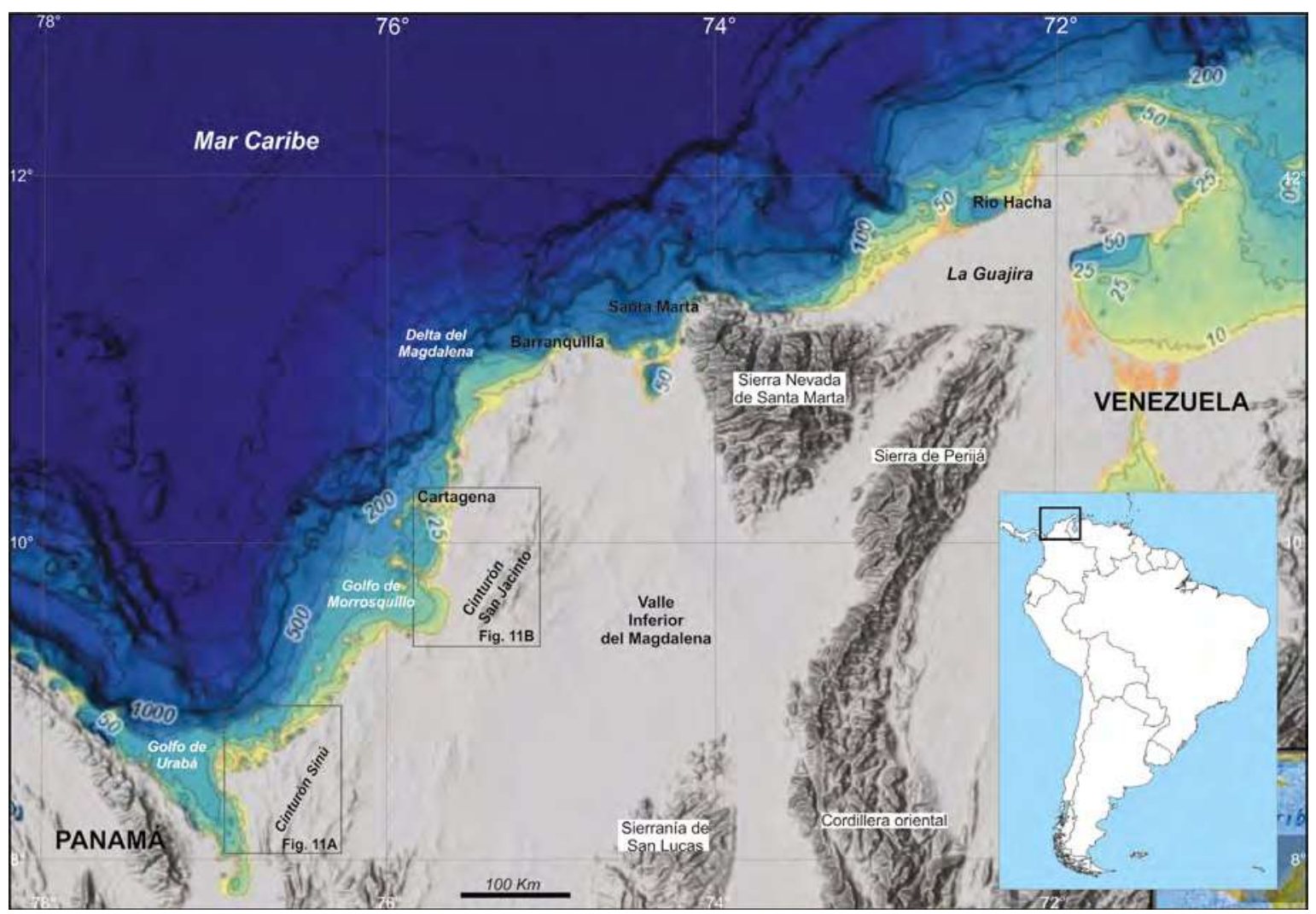

Figura 1. Localización regional del Margen Caribeño Colombiano. Los recuadros indican la localización de las Figuras 11A y 11B (tomada de https://maps.ngdc.noaa.gov/viewers/bathymetry/).

Rossello y Osorio (2016) adelantaron conceptos genéticos y morfotectónicos del diapirismo argilocinético del MCC, basados en modelos análogos realizados para estudiar el diapirismo halocinético (entre otros, Cobbold et al., 1989; Talbot, 1995). En el presente trabajo se discuten los controles tectosedimentarios del diapirismo argilocinético y se propone un provincialismo sobre su distribución en el MCC, a partir de las características tectosedimentarias de las unidades post Cretácicas y de la morfología de los plegamientos. Adicionalmente, se proponen modelos morfoestructurales esquemáticos que pretenden contribuir con el análisis de oportunidades exploratorias de hidrocarburos en el MCC, relacionadas con los mecanismos argilocinéticos.

\section{Metodología}

Se describen los aspectos morfológicos del diapirismo del MCC a partir de mapeos geológicos y cartográficos digitales de superficie y de la interpretación de algunas secciones sísmicas disponibles. Los mecanismos propuestos para el emplazamiento de estos principales rasgos morfológicos, tanto en superficie como en el 
subsuelo, se basan en resultados proporcionados por modelos analógicos específicos aplicados al diapirismo halocinético en trabajos previos (Cobbold et al., 1989; Jackson et al., 1990; Talbot et al., 1991; Weijermars et al., 1993; Jackson y Talbot, 1986, entre otros). Con respecto a los rasgos morfológicos de diapirismo argilocinético, se sintetizan numerosos ejemplos que caracterizan las principales nomenclaturas y fenómenos de expulsión, apilamiento y derrames de sedimentos fluidos de variadas formas y tamaños, frecuentemente asociados con manaderos de gases y eventos catastróficos. Se incluyen descripciones morfológicas y formacionales disponibles del diapirismo argilocinético tanto en el continente como en costa afuera del MCC (Briceño y Vernette, 1992; Carvajal et al., 2010; Carvajal y Mendivelso, 2017; Herrera-Atencio y Díaz-Mendoza, 2018; GarcíaGonzález et al., 2019).

El marco tectonoestratigráfico regional del ambiente tectosedimentario del MCC se relaciona con los modelos tectónicos vigentes generados a partir de la interacción de las placas sudamericana y Caribe. Para ello, se recopilan investigaciones e interpretaciones disponibles, que incluyen un modelo ampliamente considerado de tipo subducción y otro, aún fuertemente discutido, de tipo margen pasivo, con una incipiente convergencia transpresional dextral sobreimpuesta.

\section{Marco tectosedimentario del Margen Caribeño Colombiano}

El MCC se extiende desde el Golfo de Urabá hasta el extremo septentrional de La Guajira, sobre los confines de las placas oceánica Caribe y continental Sudamericana (Figura 1). El origen cretácico de la placa Caribe y su evolución geológica están relacionados principalmente con su interacción con las placas de Cocos, Nazca, América del Sur, América del Norte y la microplaca de Panamá (véanse múltiples referencias en Mora-Páez et al., 2019; Toussaint y Restrepo, 2020; Zapata-García y Rodríguez-García, 2020). Las características genéticas de la configuración tectónica de la convergencia de las placas Nazca, Sudamérica y Caribe y el desarrollo de la Orogenia Andina en estos confines de placas constituyen el centro de un acalorado debate que discute si su disposición actual es puramente subductante o simplemente convergente con componente transcurrente dextral. Sobre todo, la divergencia de opinión está fundamentada principalmente en la consideración del origen alóctono o autónomo de la placa Caribe (Ladd et al., 1984; Bowland, 1993; Chiarabba et al., 2016; Pérez et al., 2018; Kellogg et al., 2019). Al respecto, existe una gran cantidad de trabajos basados en datos geoquímicos, paleomagnéticos, de GPS, geomorfológicos, geofísicos y de reconstrucciones paleogeológicas que apoyan ambas hipótesis de aloctonía o autoctonía. Por esta razón, y con la finalidad de aludir a esta controversia, a continuación, se sintetizan algunos de los trabajos más característicos.

Pindell y Kennan (2009) propusieron que la placa Caribe se formó en el mar Pacífico hace aproximadamente 125 Ma como un punto caliente, y luego se movió hacia el noreste hasta la posición actual, subduciendo la placa Sudamericana. Contrariamente, Stainforth (1969) y James (2006, 2010) consideran, a partir de reconstrucciones paleogeográficas y evidencias de afloramientos claves, que la placa Caribe se formó in situ entre las placas de América del Norte y América del Sur desde el Triásico-Jurásico Temprano, prescindiendo de un escenario de subducción. Debido a estas interpretaciones confrontadas, la dinámica de la evolución tectonosedimentaria del MCC genera controversias sobre los mecanismos geotectónicos que la controlan; se consideran desde escenarios asociados con márgenes acrecionales subductantes (Duque-Caro, 1984a, 1984b; Toto y Kellogg, 1992; Flinch, 2003; Kerr y Tarney, 2005; Cerón et al., 2007; MantillaPimiento, 2007; Higgs, 2009; Pindell et al., 2005; Vinnels et al., 2010; Bezada et al., 2010; Bernal-Olaya et al., 2015a, 2015b; Mora et al., 2018; Kellogg et al., 2019; Rodríguez et al., 2021) hasta pasivos (Ali-Zade et al., 1984; James, 2006, 2009, 2010; Cobbold et al., 2007; Rossello y Cossey, 2012; Alfaro et al., 2013).

A pesar de las múltiples contribuciones científicas disponibles, las características tectónicas apoyadas por las actuales informaciones de superficie y subsuelo siguen siendo insuficientes para afirmar de modo concluyente que el mejor escenario de las placas Caribe y Sudamérica sea de una típica subducción, en el sentido de Uyeda (1982). Los principales argumentos se basan en los desplazamientos relativos de las placas, obtenidos por estaciones de GPS estratégicamente instaladas en la región (Kellogg et al., 2019; MoraPáez et al., 2019). A pesar de que las variaciones en las direcciones e intensidades de estos desplazamientos no resultan ser muy claros para mostrar una convergencia determinante de un contexto típico de subducción esta interpretación está fuertemente instalada en la comunidad geológica colombiana (Figura 2). Estos análisis de la conformación regional y de los desplazamientos relativos entre las placas Caribe y Sudamérica determinan una traslación oriental de ambas con direcciones y velocidades equivalentes que 
no apoyan la subducción de la primera. Además, se comprueba la ausencia en el MCC de las evidencias características, habitualmente aceptadas de subducción (Stern, 1998, 2002); entre estas, se mencionan las siguientes: i) la inexistencia de un arco magmático calcoalcalino característico, ii) la total ausencia de rasgos geomorfológicos de altas cordilleras en tierra y fosas en el mar, iii) la distribución espacial de la sismicidad no compatible con la continuidad y ángulo de inclinación de la supuesta superficie de subducción y iv) la falta de un prisma acrecional con características petrotectónicas consistentes. A partir de la ausencia de estos argumentos se considera más consistente admitir un ambiente convergente actual sobre el MCC, orientado oblicuamente, pero aún no subductante (Rossello y Cossey, 2012).

La convergencia sobre el segmento del MCC, comprendido entre el Golfo de Atrato y el área de Barranquilla (Figura 1), genera un campo de esfuerzos con su principal máximo horizontal dispuesto sublatitudinalmente, que determina, en función de la disposición de los sectores austral (SO-NE) y septentrional (NNO-SSE), componentes transpresionales dextrales con intensidades variables (Figura 2). En el sector austral, el carácter más transtensional posibilita el desarrollo de plegamientos de tipo gravitatorio; en cambio, en el sector septentrional el carácter más transpresional favorece el desarrollo de pliegues más elongados y típicamente compresionales. Este contexto determina a partir de su funcionamiento desde el Oligoceno la exhumación del cinturón SinúSan Jacinto (que en general no supera los 300 m.s.n.m.), el desencadenamiento de deslizamientos gravitatorios con vergencia hacia el norte y la traslación oriental de los abanicos submarinos relacionados con las descargas sedimentarias de los ríos Cauca y Magdalena.

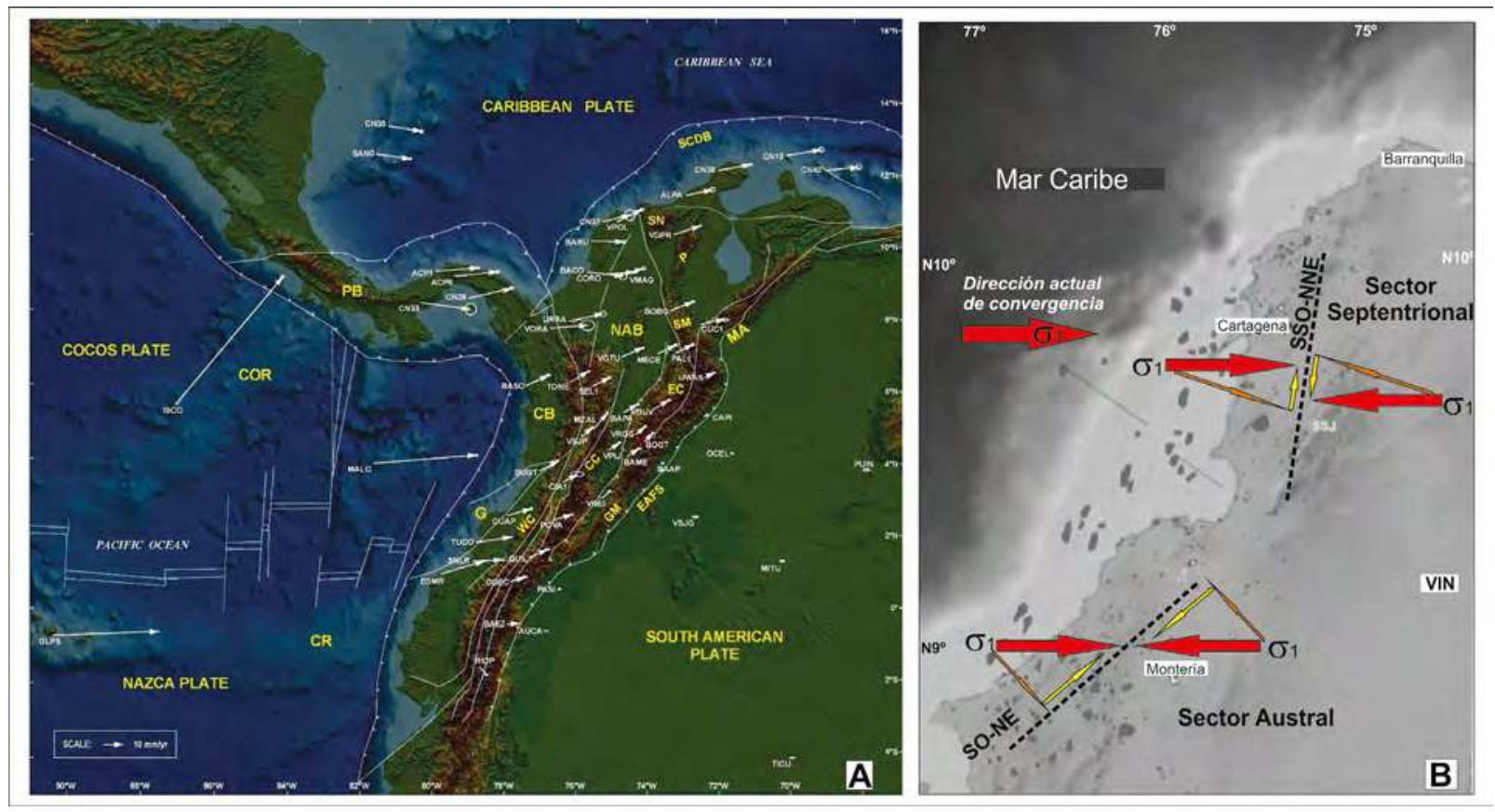

Figura 2. A. Distribución de datos de GPS en el extremo NW de Sudamérica que muestran la similitud en dirección y módulo de desplazamientos de puntos fijos en las placas Caribe y Sudamérica, que no apoyan un escenario subductante (tomada de Kellogg et al., 2019). B. Esquema del escenario convergente actual y los componentes compresionales y traslacionales diferenciales del campo de esfuerzo por la disposición del sector austral (SO-NE) más transtensivo y del sector septentrional (SSO-NNE) más transpresivo.

Desde el punto de vista cronoestratigráfico, el MCC exhibe secuencias sedimentarias a lo largo de su historia depositacional desde el Cretácico, con diferentes granulometrías, tasas de sedimentación y distribución espacial; estas secuencias se traslapan progresivamente hacia el norte a través del tiempo y el espacio (Figura 3). Así, el registro sedimentario evolucionó inicialmente desde un contexto tectónico extensional, asociado a la apertura del Caribe, donde sobre el margen continental se desarrollaron depocentros volcano-sedimentarios de tipo rift, limitados preferencialmente por bordes activos fallados con vergencia hacia el norte (véanse discusiones en Cediel et al., 2003; Barrero et al., 2015; Mora et 
al., 2018; Lozano y Zamora, 2014). A medida que la costa migraba hacia el norte por la continentalización del MCC, estas secuencias fueron sobreimpuestas progresivamente por acumulaciones sedimentarias alimentadas por los aportes silicoclásticos de los paleocursos de los ríos Magdalena y Cauca como los principales responsables del acarreo de los volúmenes sedimentarios erosionados desde los relieves de las cordilleras Oriental, Central y Occidental (Rossello et al., 2011).

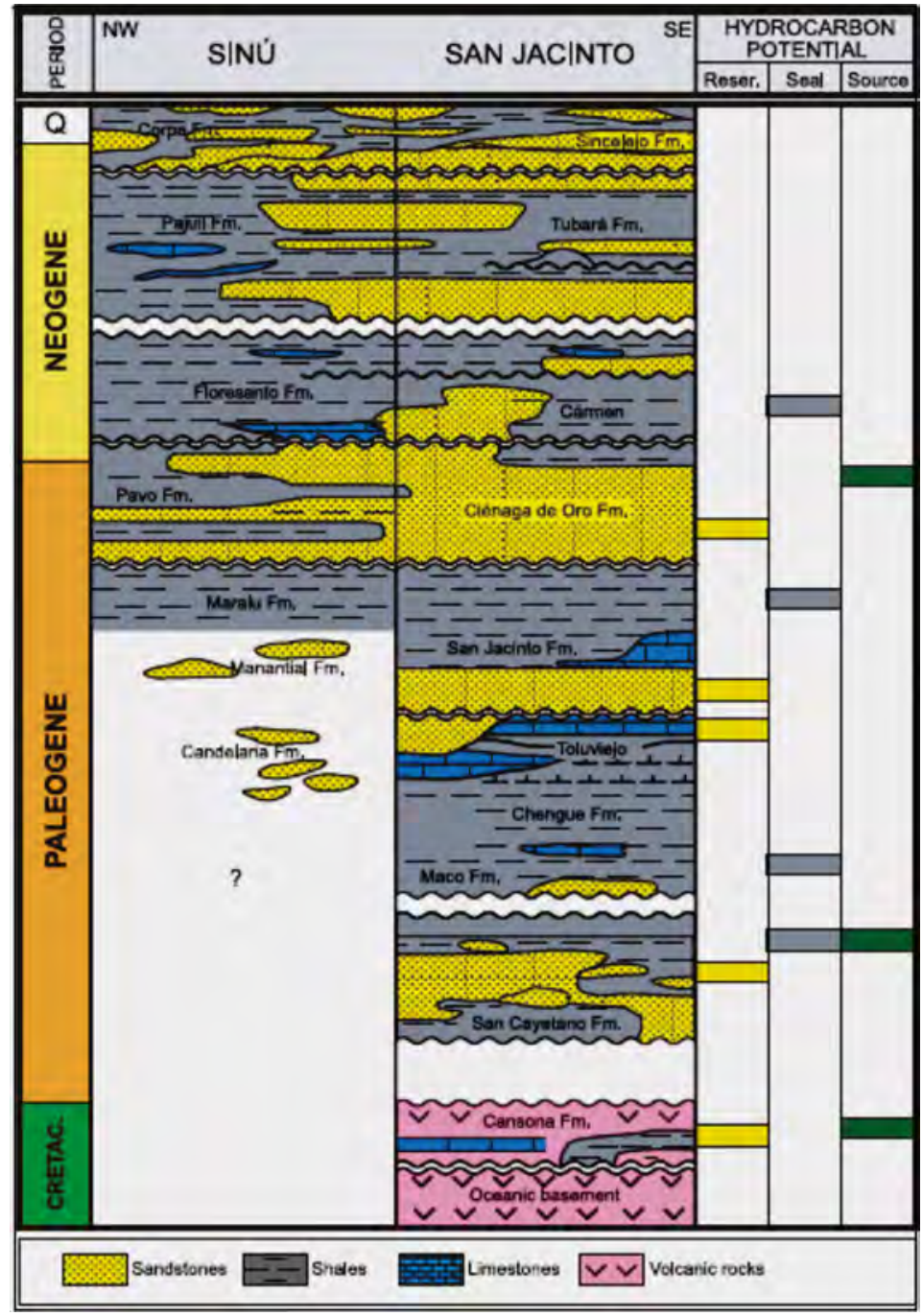

Figura 3. Columna litoestratigráfica generalizada del Cinturón Sinú-San Jacinto y los principales niveles atribuidos con potencial de rocas madres y reservorios de hidrocarburos (tomada de Barrero et al., 2015).

Así, las secuencias turbidíticas más distales, constituidas por materiales pelíticos, fueron sucesivamente traslapadas por el avance hacia el norte de secuencias litorales y plataformales progradantes, más arenosas y con algunas intercalaciones carbonáticas (Figura 4A). Sin embargo, a partir del Mioceno, por el acortamiento horizontal generado por la convergencia entre las placas Caribe y Sudamérica, el MCC desarrolla el Cinturón Plegado del Sinú-San Jacinto (CPSS). Este relieve acusa una exhumación progresiva que comienza a actuar como una barrera parcial para el escurrimiento del río Cauca. Por lo tanto, con la finalidad de continuar transportando su carga sedimentaria, debe modificar su trayectoria para confluir con el río Magdalena y, así, alcanzar su nivel de base en el mar Caribe (Figura 4B).

Como consecuencia del bloqueo del río Cauca, se produce una notable disminución de la tasa de sedimentación de las secuencias Plio-pleistocenas en el sector austral del MCC $y$, contrariamente, un fuerte incremento en el norte que fortalece la conformación del enorme abanico submarino 
del Magdalena. Debido al mayor desplazamiento oriental acumulado de la placa Caribe sobre la cual se apoya la desembocadura del río Magdalena, las secuencias infrayacentes de su delta se trasladan progresivamente hacia esa dirección (Figura 4C).

Asociado con los cambios de tasas de sedimentación, el diapirismo, en el sector austral del MCC, tiende a desarrollarse de modo más continuo desde niveles pelíticos profundos, atravesando toda la secuencia Neógena. En cambio, el diapirismo en el sector septentrional tiende a ser bloqueado por la mayor tasa de sedimentación que exhiben las secuencias Plio-pleistocenas, aunque el fallamiento extensional sinsedimentario puede facilitar el ascenso diapírico de volúmenes fosilizados (Figura 4C).

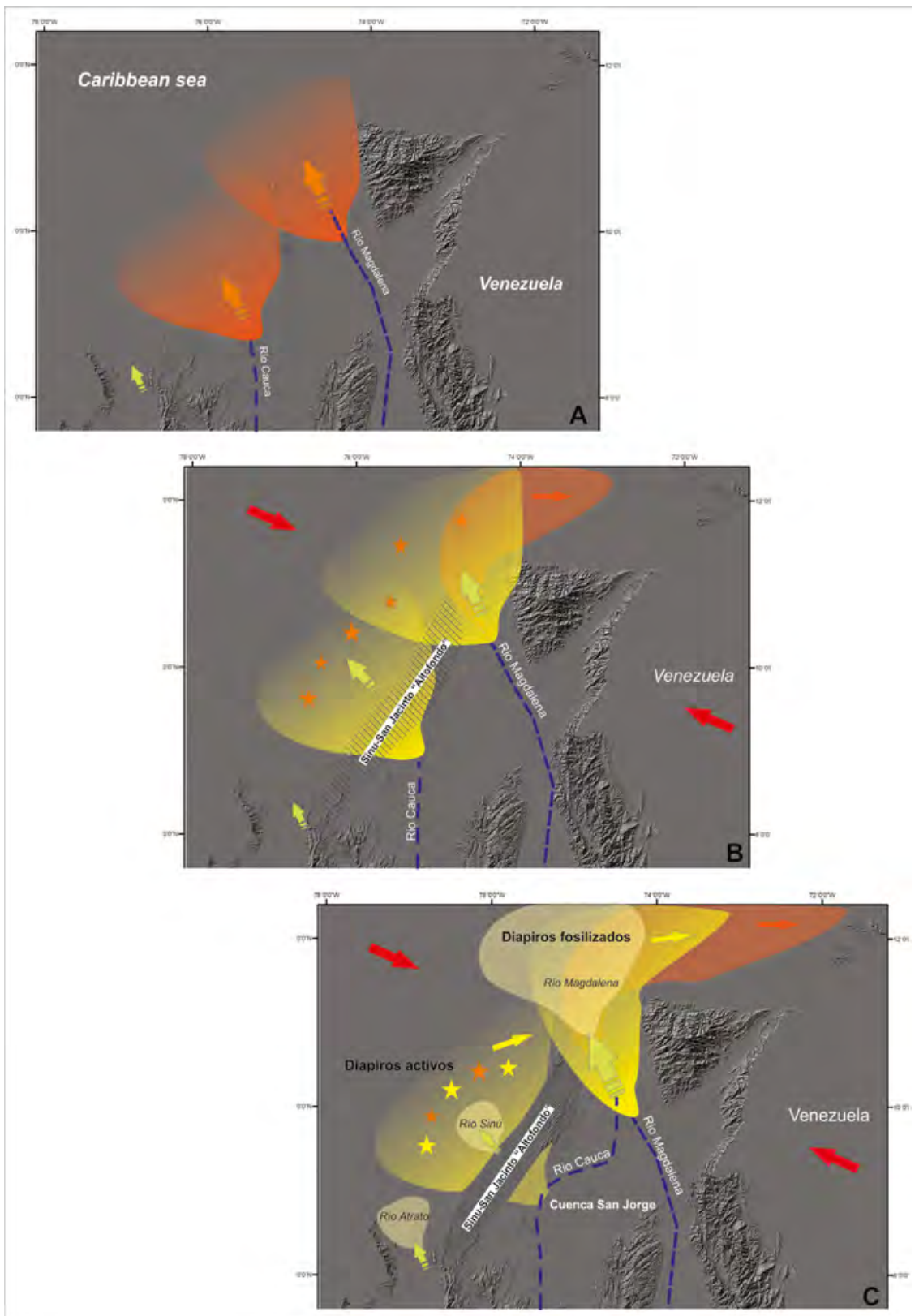

Figura 4. Modelo evolutivo esquemático del Margen Caribeño Colombiano, relacionado con la generación del diapirismo argilocinético (modificado de Rossello et al., 2011). A. Descargas tempranas de los paleo ríos Cauca y Magdalena y avance progradante del litoral. B. Comienzo de la restricción de la descarga del paleo río Cauca por la exhumación del Sinú-San Jacinto y comienzo de la generación de diapirismo de las secuencias infrayacentes (estrellas). C. Bloqueo total y coalescencia tardía del río Cauca sobre el río Magdalena que incrementa la tasa sedimentaria fosilizando los diapiros anteriores (estrellas naranjas) y los que continúan en actividad al sur (estrellas amarillas). 


\section{Controles sedimentarios del diapirismo}

De acuerdo con la terminología habitualmente utilizada, los diapiros (de la palabra griega $\delta 1 \alpha \pi \varepsilon i ́ p \varepsilon ı v$ diapeirein, 'perforar' o 'atravesar') son intrusiones dúctiles, cualquiera sea su dinámica y naturaleza, que ocurren en la corteza. Esto se aplica para volúmenes de diferentes materiales tanto de origen magmático como sedimentario y con densidades inferiores a sus encajantes, debido fundamentalmente a la acción de la fuerza gravitatoria (Braunstein y O’Brien, 1968; Nordgard-Bolas et al., 2004).

La distribución, actividad, productos de erupción y mecanismos de formación de volcanes de lodo terrestres han sido reconocidos, descriptos y estudiados durante más de 200 años (Goad, 1816); sin embargo, la investigación de volcanes de lodo submarinos comenzó hace 30 años, gracias al avance de la calidad de detección de las metodologías de relevamiento (Milkov, 2005). Este desarrollo tecnológico de los métodos de relevamientos de campo ha producido un incremento sustancial de trabajos y publicaciones relacionadas con la descripción y génesis de la argilocinesis, responsable de los diapiros y volcanes de lodo, sobre todo, en regiones sometidas a la exploración de hidrocarburos. El diapirismo argilocinético ha sido localizado en diversos contextos tectónicos tanto de tipo compresivos (e.g. Barber et al., 1986; Yassir, 1989; Brown, 1990; Cita et al., 1996; Gardner, 2001; Summer y Westbrook, 2001; Somoza et al., 2003; Deville et al., 2006; Istadi et al., 2012) como extensionales, a lo largo de diversos márgenes continentales (e.g. Ivanov et al., 1996; Van Rensbergen et al., 1999; Cohen y McClay, 1996; Graue, 2000; Gardner, 2001; Morley, 2003); incluso, ocurre en regiones intracontinentales emergidas como Asia Central (e.g. Ivanov et al., 1996; Hovland et al., 1997; Limonov et al., 1997; Milkov, 2000, 2005; Davies y Stewart, 2005; Wu, 2005). Por la naturaleza de los materiales involucrados, los mecanismos halocinéticos o argilocinéticos se asocian con secuencias sedimentarias poco consolidadas en ambientes depositacionales, con tasas de sedimentación altas. Se han descrito las características morfológicas y composición de casi 2000 volcanes de lodo en todo el mundo, particularmente los ubicados a lo largo del Cinturón Activo Alpino-Himalaya (Dimitrov, 2002), y en diversos márgenes pasivos continentales del océano Atlántico, donde comparten los mismos ambientes sedimentarios con diapirismo halocinético.

Los diapiros argilocinéticos están constituidos por volúmenes de sedimentos finos y fluidos que mediante su extrusión pueden movilizarse verticalmente varios kilómetros desde sus horizontes de origen y llegar, incluso, hasta la superficie para aflorar como volcanes de lodo. Los materiales pelíticos poseen baja densidad y gran fluidalidad por los altos contenidos acuosos adquiridos al momento de su depositación. A partir de las condiciones ambientales de depositación, los contenidos acuosos disminuyen progresivamente por su expulsión durante el soterramiento y diagénesis (Figura 5).

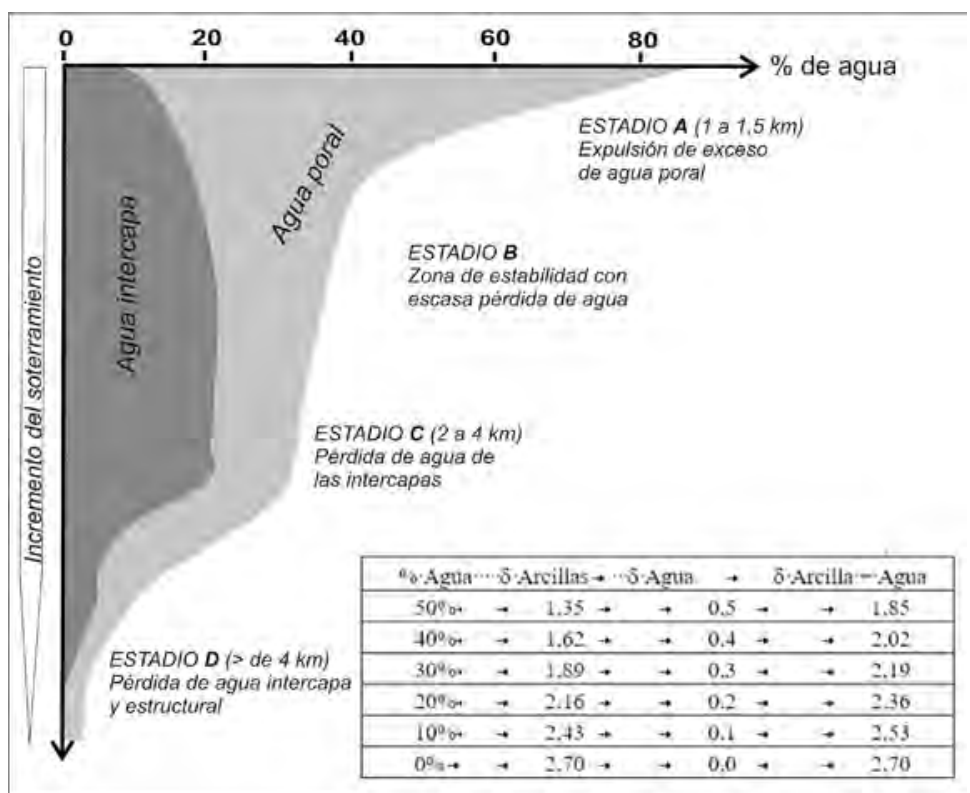

Figura 5. Cálculo estimativo de la densidad de un lodo en función del \% de agua contenida. Las densidades son en general inferiores a $2,2 \mathrm{~g} / \mathrm{cm}^{3}$, y gradientes térmicos más bajos del orden de $20^{\circ} \mathrm{C} / \mathrm{km}$. Cuadro esquemático de los distintos estadios de expulsión de aguas de un sedimento-roca en función del soterramiento (adaptado de Bloch et al., 2002). 
De acuerdo con varios autores (Kerr et al., 1970; Pettijohn, 1975; Potter et al., 1980; Chamley, 1989; Nordgard-Bolas et al., 2004; Rossello, 2018), los contenidos iniciales de agua poral y de intercapa pueden alcanzar valores de más de $40 \%$. Debido al rápido soterramiento por potentes secuencias más densas que lo suprayacen, estos fluidos pueden permanecer confinados sin poder ser expulsados durante la compactación y/o diagénesis. Kerr et al. (1970) consideran que las arcillas con movilidad tixotrópica (particularmente caolinita), con densidad reducida por importantes contenidos de agua y sometidas a fuertes presiones por gases y sobrecarga tectónica son aparentemente las más adecuadas para generar diapirismo.

\section{Modelización analógica}

Nettleton (1934) y Barton (1933) comenzaron la realización de modelados físicos para comprender los procesos dinámicos participantes en la generación del diapirismo salino del Golfo de México y, de este modo, interpretar sus morfologías y patrones evolutivos. Cobbold et al. (1989) realizaron con mezclas de siliconas los primeros modelos analógicos que permitieron reconocer la influencia de diferentes tasas de sedimentación sin- a post-sedimentarias de secuencias suprayacentes sobre los niveles menos densos y viscosos que producen el desarrollo del diapirismo simulado. De este modo, se comprobó que la tasa de depositación de las sucesivas secuencias sedimentarias suprayacentes influye en la determinación de inestabilidades por soterramiento, al modificar las condiciones de presión y temperatura dependientes de la profundidad. Observaron que, en función de las tasas de sedimentación de las secuencias suprayacentes, se puede bloquear o desencadenar el proceso ascendente de las secuencias infrayacentes menos densas.

Con tasas de sedimentación muy altas se producen bloqueos; por el contrario, tasas muy lentas contribuyen con la evolución sinsedimentaria ascendente del diapirismo. En este último caso, se alcanza el equilibrio en niveles corticales más someros, o incluso llegan a alcanzar la misma superficie y formar volcanes de lodo y coladas (Figura 6).

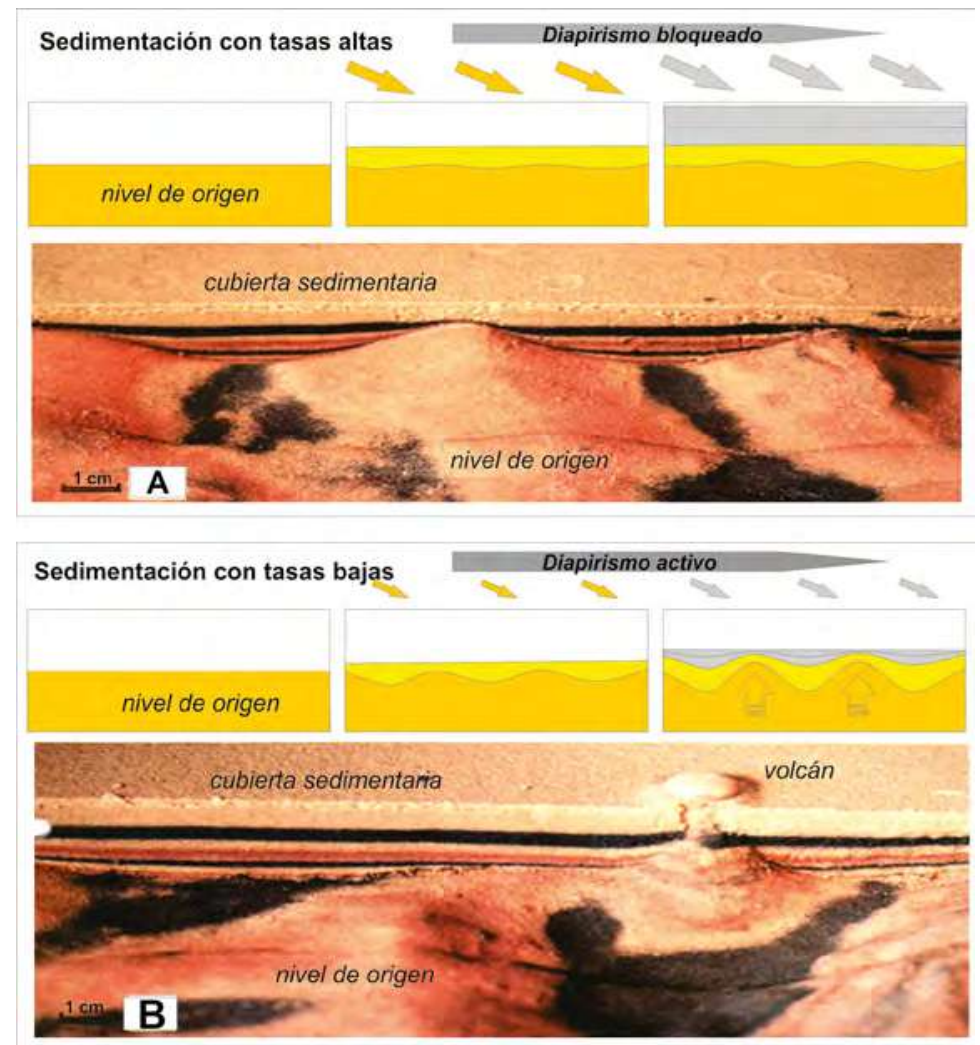

Figura 6. Vistas de los primeros modelos físicos analógicos y esquemas simplificados sobre la generación de diapirismo en función de las tasas de sedimentación de las secuencias suprayacentes (nivel de origen: siliconas; cubierta sedimentaria: arenas). A. Bloqueo del diapirismo por tasa de sedimentación alta. B. Evolución del diapirismo sinsedimentario incentivado por tasa de sedimentación baja. La escala: 1 cm (tomado de Cobbold et al. 1989). 
Jackson y Talbot (1986), Jackson et al. (1990), Talbot et al. (1991) y Weijermars et al. (1993) desarrollaron modelos físicos con diferentes materiales analógicos que resultaron geométrica y dinámicamente similares a los patrones de extrusión de fluidos viscosos debido a convección térmica. Se comenzó a comprobar que los niveles suprayacentes más densos y que exceden un espesor crítico (Nettleton y Elkins, 1947; Bishop, 1978; Cobbold et al., 1989; Vendeville y Jackson, 1992a, 1992b; Davison et al., 1993) pueden hacerse lo suficientemente resistentes como para ser impenetrables a los diapiros y bloquear su evolución. Un tectonismo que produzca fallamientos que afecten la continuidad de los horizontes bloqueadores, particularmente en escenarios extensionales, puede contribuir con el diapirismo al facilitar vías de transporte verticales (Schultz-Ela et al., 1993; Jackson y Vendeville, 1994; Jackson et al., 1994).

A partir del modelado analógico, se comprueba que el principal disparador del diapirismo es el desequilibrio de densidad. La menor densidad de los materiales infrayacentes de naturaleza sedimentaria resulta de la presencia de aguas de formación que por su rápida depositación no tuvieron la oportunidad de ser expulsadas (Figura 5). De esta manera, se encuentran en desequilibrio con respecto a la mayor densidad de los materiales suprayacentes, por lo tanto, no resultan indispensables escenarios tectónicos que aporten esfuerzos tangenciales para producir el diapirismo (Cobbold et al., 1989; Talbot, 1995). De este modo, se ha vuelto cada vez más común modelar cuencas sedimentarias que utilizan sobrecargas de partículas sueltas arenosas (Cobbold et al., 1989; Vendeville y Jackson, 1992a, 1992b), colecciones de bloques cabalgantes (Davison et al., 1993) o materiales plásticos que fluyen a velocidades no lineales (Talbot, 1992; Podladchikov et al., 1993).

Talbot (1995), basado en el análisis de la relación entre las tasas verticales de acumulación de sedimentos y la velocidad de ascenso del diapiro, estableció que la morfología pasiva del diapirismo salino está moldeada por la propia evolución de su enterramiento, debido a los siguientes procesos: a) la relación entre la velocidad y potencia de la acumulación local neta de los sedimentos suprayacentes $(\mathrm{A}=$ depositación menos compactación), denominada tasa de sedimentación $($ Aggradation $=\dot{\mathrm{A}}) \mathrm{y}$ b) $\mathrm{R}$ el incremento neto del relieve ascendente del diapiro $(\mathrm{R}=$ ascenso menos disolución) a una tasa de ascenso neto del diapiro (Rise $=\dot{\mathrm{R}}$ ). De este modo, se puede determinar y predecir la morfología del diapiro de acuerdo con las siguientes relaciones (Figura 7).

Si la relación es $\dot{\mathrm{R}} \gg>\dot{\mathrm{A}}$, es decir que el ascenso es dominante con respecto a la sedimentación, por ejemplo, $\dot{\mathrm{R}} / \dot{\mathrm{A}}> \pm 100$, el diapiro se extruye hacia la superficie perforando sus secuencias suprayacentes y se ensancha plegando e invirtiendo las capas de su encajante, posibilitando incluso el derrame en la superficie (Figura 8). Por debajo de este rango (donde $\dot{\mathrm{R}} / \dot{\mathrm{A}}<0,01$ ), el contacto superior se eclipsa (enterrado temporariamente a profundidades desde las cuales puede todavía evolucionar su ascenso) o incluso ocluido (enterrado debajo del grosor crítico de la secuencia suprayacente), y, por lo tanto, es incapaz de elevarse nuevamente de forma autónoma.

Si la relación es $\dot{A}>>\dot{R}$, es decir que la sedimentación es dominante, el diapiro se bloquea, y si el proceso es singenético con el ascenso, el diapiro se angosta hacia la superficie, ya que se produce el traslapamiento mediante discordancias de crecimiento de las secuencias singenéticas. La relación $(100>\mathrm{R} / \mathrm{A}>$ $0,01)$ significa que son limitados por el enterramiento y extrusión. De este modo, una agradación más rápida que el ascenso diapírico $(\mathrm{R} / \mathrm{A}<1)$ hace que el ascenso sea frenado y adelgazado hacia arriba de sus contactos (Figura 7).

Si la relación es $\dot{\mathrm{A}}=\dot{\mathrm{R}}$, es decir que ninguno de los factores es dominante, los márgenes del diapiro, con respecto a su encajante, tienden a ser verticales (Figura 7).

Si bien los modelos analógicos mencionados fueron inicialmente realizados para comprender la morfología de diapiros salinos debido a las variaciones de las tasas de sedimentación sin- a post-genética, también pueden aplicarse a los diapiros de lodo por ser procesos gravitatorios análogos. 


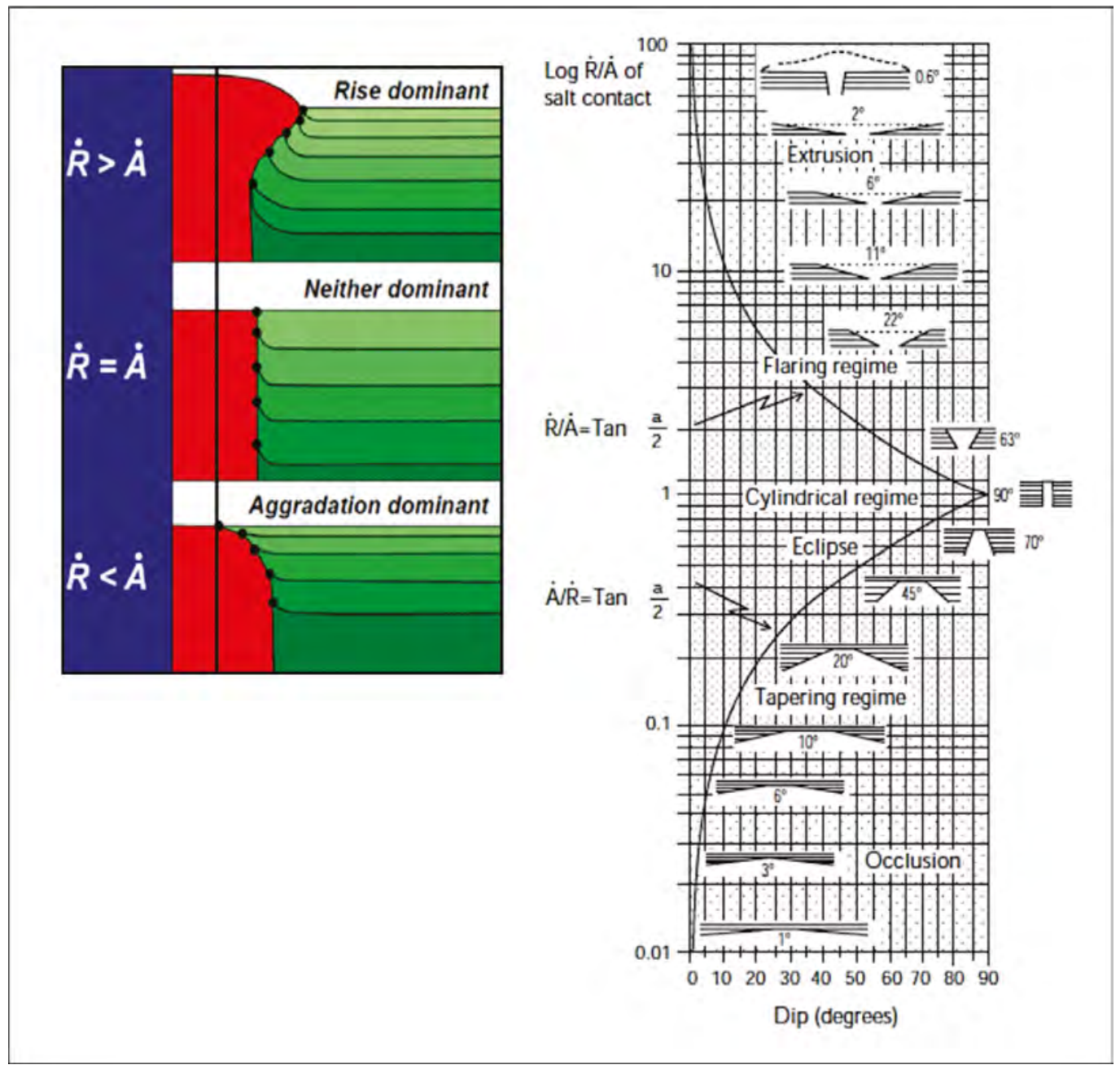

Figura 7. Relaciones entre las tasas de sedimentación $(\dot{\mathrm{A}})$ y de ascenso diapírico $(\dot{\mathrm{R}})$ controlantes de la generación, evolución y morfología que adquieren los diapiros salinos (tomada de Talbot, 1995).

\section{Los volcanes de lodo}

El diapirismo genera una serie de rasgos morfológicos que permiten reconocer su evolución en función del tiempo y la profundidad, y también logran evidenciar la estimación de los contrastes de densidad de los volúmenes involucrados con respecto a sus encajantes. Cuando un diapirismo argilocinético alcanza la superficie, genera un volcán de lodo con morfologías y tamaños muy variables, ya que pueden tener desde escasos metros a unos pocos kilómetros de diámetro y varios cientos de metros de altura. Un volcán de lodo es considerado como una geoforma que tiene una expresión topográfica definida, dada por la acumulación de flujos producidos por el diapirismo argilocinético que escapan hacia la superficie terrestre o marina cuando encuentran un conducto o vía de escape que, generalmente, es una falla o fractura (Braunstein y O’Brien, 1968) (Figura 8).
Además de la diferencia de densidad entre los volúmenes que se movilizan desde secuencias fuentes profundas y la cubierta sedimentaria superior más densa, estos procesos argilocinéticos pueden estar estimulados por la compresión tectónica y la presencia de un alto contenido de gases. Vernette et al. (1992) y Stewart y Davies (2006) propusieron que los volcanes de lodo son esencialmente la expresión más superficial de la existencia de fracturamientos que constituyen las vías alimentadoras que los comunican con la unidad estratigráfica que le sirve de fuente para el material que expulsan. Kerr et al. (1970) describen la presencia de volcanes de lodo a lo largo de fallamientos que han controlado su emisión y el transporte hacia la superficie de fragmentos de materiales consolidados areniscosos, producto del arranque de los encajantes (Higgins y Saunders, 1974; Barber et al., 1986; Brown, 1990). 
Kholodov (1983 en Akhmanov y Mazzini, 2007) propuso la siguiente clasificación de la morfología de los edificios volcánicos de lodo: 1) edificio volcánico cónico "clásico" con cráter principal y estratificación de los flujos de lodo periféricos sobre sus laderas que reflejan la erupción periódica; 2) protuberancia rígida del cuello de lodo, típicamente debido a su alta viscosidad y, por lo tanto, capaz de formar colinas empinadas; 3) área pantanosa; contrario al anterior por su desarrollo escasamente prominente, debido a su baja viscosidad, el lodo se extiende sobre un área grande; 4) depresión “colapsada sinclinal” o cubeta, donde una disminución del aporte o reflujo produce una depresión, y 5) el lago fangoso del cráter, es el tipo más abundante en varias áreas volcánicas de lodo muy fluido.

Cuando los volcanes están constituidos por materiales poco fluidos se presentan como cerros generalmente cónicos o en forma de domos con laderas convexas y cima plana o en artesa (Figura 9).

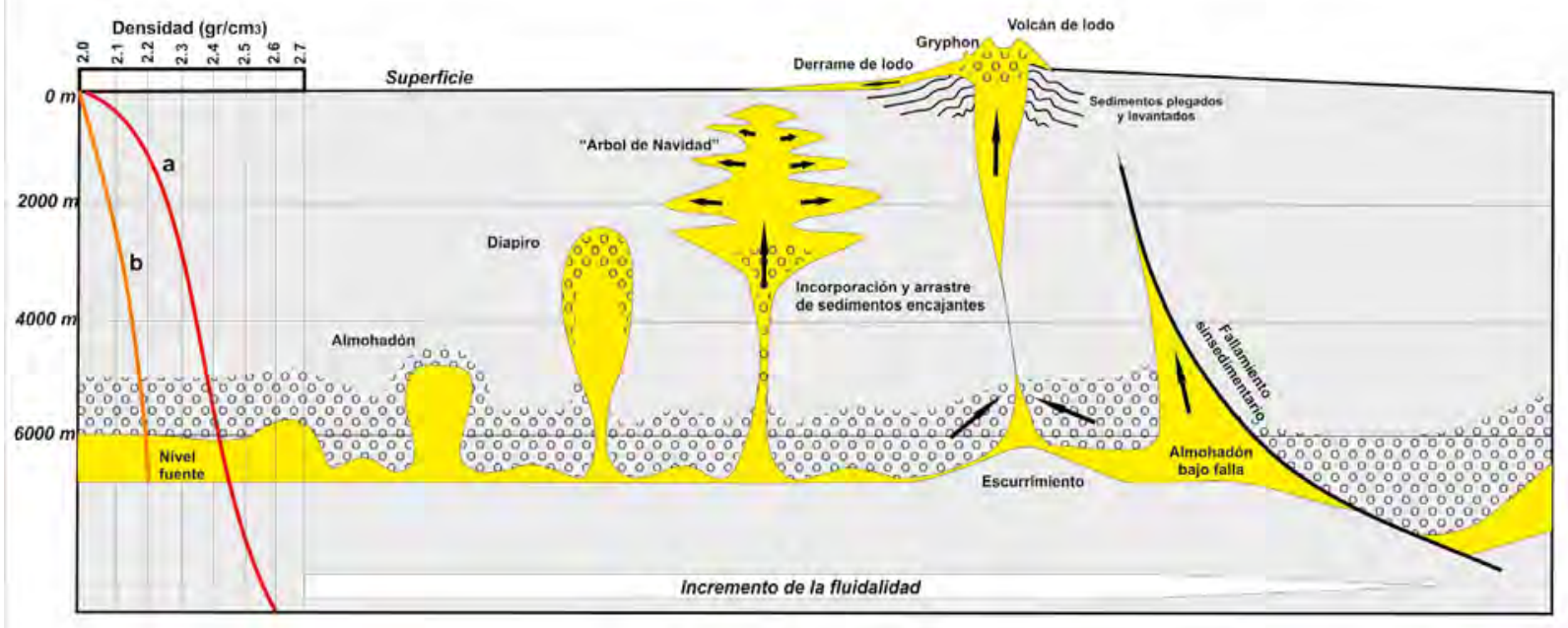

Figura 8. Diferencias morfológicas esquemáticas de diapiros argilocinéticos sin- y post-sedimentarios en función de las velocidades de emplazamiento con respecto a la depositación de las secuencias que los post-datan y de sus grados de fluidalidad.

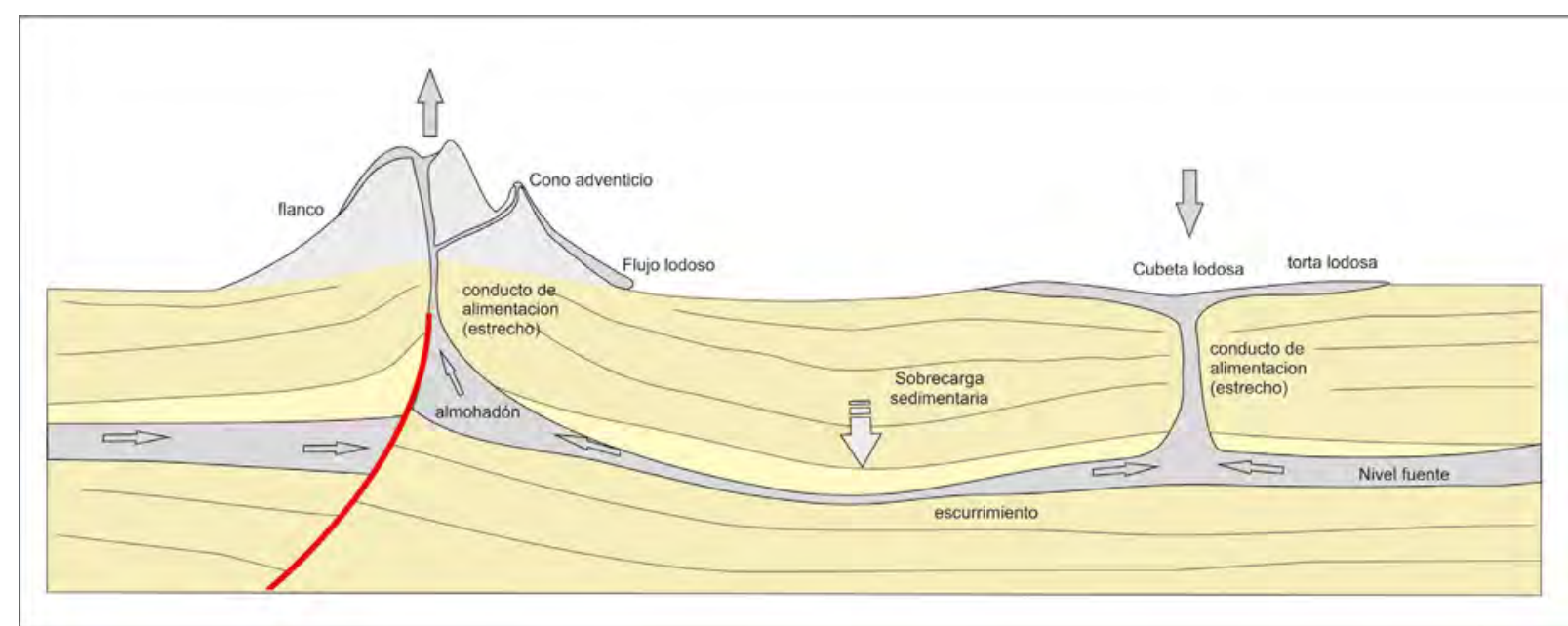

Figura 9. Esquemas morfológicos del diapirismo argilocinético en función de las pendientes de sus flancos, debido a la fluidalidad de sus lodos: de tipo cónico (poco fluidos) o de cubeta o torta (muy fluidos). Suelen ocurrir pequeños conos o cráteres adventicios (gryphon) debido a escapes por fuera de la cresta o sobre los flancos de la estructura principal facilitados por conductos de alimentación subordinados. 
Pueden alcanzar alturas varias veces decamétricas y estar formados no solamente por el apilamiento de sucesivas acumulaciones de lodos, producto de erupciones anteriores, sino también por la deformación del terreno infrayacente generada por diapirismo. En cambio, cuando los materiales que los integran son más fluidos, no forman relieves significativos y pueden constituir una cubeta de lagunas de lodo en vez de generar relieves positivos, favorecidos por pérdida de su dinámica ascendente. Además, se reconocen los grifos o cráteres adventicios que se producen por una emisión subordinada y aislada del conducto principal

A partir del estudio de los volcanes de lodo en el mar Negro, se ha propuesto la siguiente clasificación morfotectónica, teniendo en cuenta la fluidalidad y tamaño (Limonov et al., 1997; Ivanov et al., 1996; Wiedicke et al., 2001): a) conos muy grandes, 100-150 m de altura, 2,5 km de diámetro, 2-6 de inclinación de la pendiente de sus flancos, parte superior compleja, considerados con una evolución longeva; b) conos de tamaño mediano, 60-80 m de altura, $1,5 \mathrm{~km}$ de diámetro, forma ovalada-circular, flujos confinados radiales, sin cráter bien definido, 4- $11^{\circ}$ de inclinación de la pendiente de sus flancos, probablemente característicos de erupción única, y c) edificios de forma irregular, en montículos de 20-30 m de altura, 1,8 km de diámetro, topografía rugosa, considerados más jóvenes y más activos. De acuerdo con la dinámica de los flujos y reflujos y con la fluidez de emisión de materiales lodosos, Kopf (2002) establece una diferencia de los edificios argilocinéticos basado en las pendientes de sus flancos; cuando son inferiores a $5^{\circ}$ los considera cubetas o tortas. GonzálezMorales et al. (2015) realizaron modelos analógicos no dimensionados que sugieren una relación directa entre el contenido de materia orgánica (TOC) del lodo y la altura máxima de los domos diapíricos. La morfología final del volcán de lodo es una combinación de los tipos comunes descritos anteriormente, porque depende de la viscosidad del lodo y la etapa de su desarrollo, ya que suele mostrar diferentes fases cíclicas durante la historia de su actividad. Incluso, se debe considerar en el análisis de su morfología los eventos catastróficos y períodos de inactividad relativa, caracterizados por una actividad moderada o ínfima. Por tal razón, en una misma área pueden coexistir volcanes de lodo que exhiban su propio período de actividad catastrófica, seguido por episodios de emanaciones tranquilas, y los efectos inherentes de los diferentes procesos erosivos, climáticos y condiciones ambientales de preservación.

\section{Provincialismo de la distribución del diapirismo en el MCC}

La evolución tectosedimentaria del MCC determinó a partir del Cretácico un progresivo soterramiento de secuencias más distales pelíticas (tipo pro-delta) ricas en contenidos acuosos por secuencias posteriores más densas y con mayores tasas de sedimentación (Figura 4). El carácter del soterramiento de estos volúmenes progradantes influye sobre la posibilidad que tienen las secuencias pelíticas infrayacentes de expulsar sus aguas de formación. De acuerdo con la velocidad de sedimentación de las secuencias que producen el soterramiento, las pelitas infrayacentes quedarán sobrepresionadas, pero con menores densidades relativas por los contenidos acuosos que no han tenido la oportunidad de expulsar. Este contexto genera una inestabilidad de estos volúmenes debido al desequilibrio de densidades (Figura 10).

Las manifestaciones de diapirismo argilocinético en el MCC se presentan en una franja del margen caribeño que se extiende desde el golfo de Urabá hasta la región de Barranquilla (localidad de Ciénaga Grande, cercana a Santa Marta, Figura 1), lo que incluye áreas marinas y terrestres como el Cinturón del Sinú (Figura 11). Carvajal et al. (2010) y Carvajal (2016) realizan un detallado inventario del volcanismo de lodo, donde describen sus morfologías, los materiales eyectados y los impactos generados. Aristizábal et al. (2009) y Quintero-Ramírez (2012) describen evidencias sísmicas de diferentes tipos de diapirismo en la plataforma continental del MCC.

El estilo morfoestructural del MCC que se aprecia a lo largo del Cinturón Sinú-San Jacinto es muy diferente, ya que las características tectónicas se asocian con un fallamiento extensional que acomoda secuencias suprayacentes potentes donde son más frecuentes los bloqueos del diapirismo. Basados en esta variabilidad de las características depositacionales de las secuencias sin- a post-depositacionales asociados, Rossello y Osorio (2016) identifican un provincialismo regional del diapirismo que se expresa por sus rasgos geomorfológicos superficiales e interpretaciones de relevamientos sísmicos.

El diapirismo en el sector austral del MCC (Sinú) se caracteriza por el desarrollo asociado a un plegamiento gravitatorio, que se caracteriza por grandes cubetas sinclinales separadas por anticlinales apretados 
(Figura 12). Los sinclinales generados en ambientes dominados por procesos gravitacionales exhiben relaciones entre el largo (ejes) vs anchos más semejantes (Medwedeff, 1989). En este sentido, Duque-Caro (1984a, 1984b, 1990) al describir el CSSJ reconoce que el diapirismo es el factor deformante más importante, debido al peso gravimétrico de los sedimentos turbidíticos sobre los menos densos pelágicos y hemipelágicos y que los esfuerzos compresionales laterales son un factor menor. Además, propone una clara diferenciación entre las características tectosedimentarias del Cinturón San Jacinto (al norte), con secuencias marinas predominantemente cretácicas y eocenas, y el Cinturón Sinú (al sur) con secuencias predominantemente oligocenas a pliocenas.

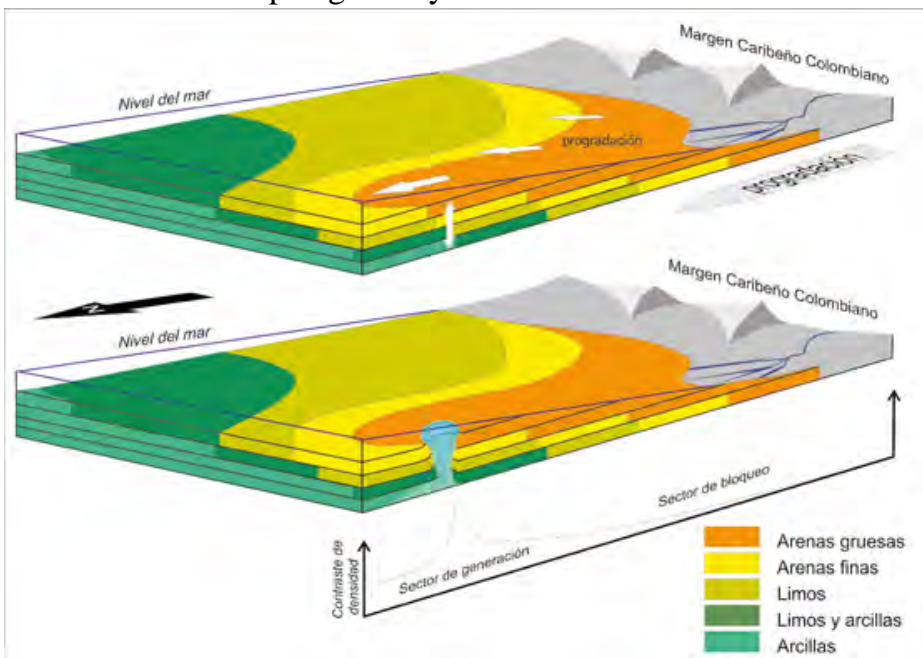

Figura 10. Evolución esquemática del desarrollo de diapirismo argilocinético sobre el Margen Caribeño Colombiano, a partir de la progradación progresiva hacia el norte de secuencias más densas proximales a la costa sobre las pelíticas infrayacentes distales saturadas en agua. En los sectores donde la secuencia más densa comienza a sobreponerse sobre las menos densas, se genera un ambiente propicio para el desarrollo de diapirismo argilocinético.

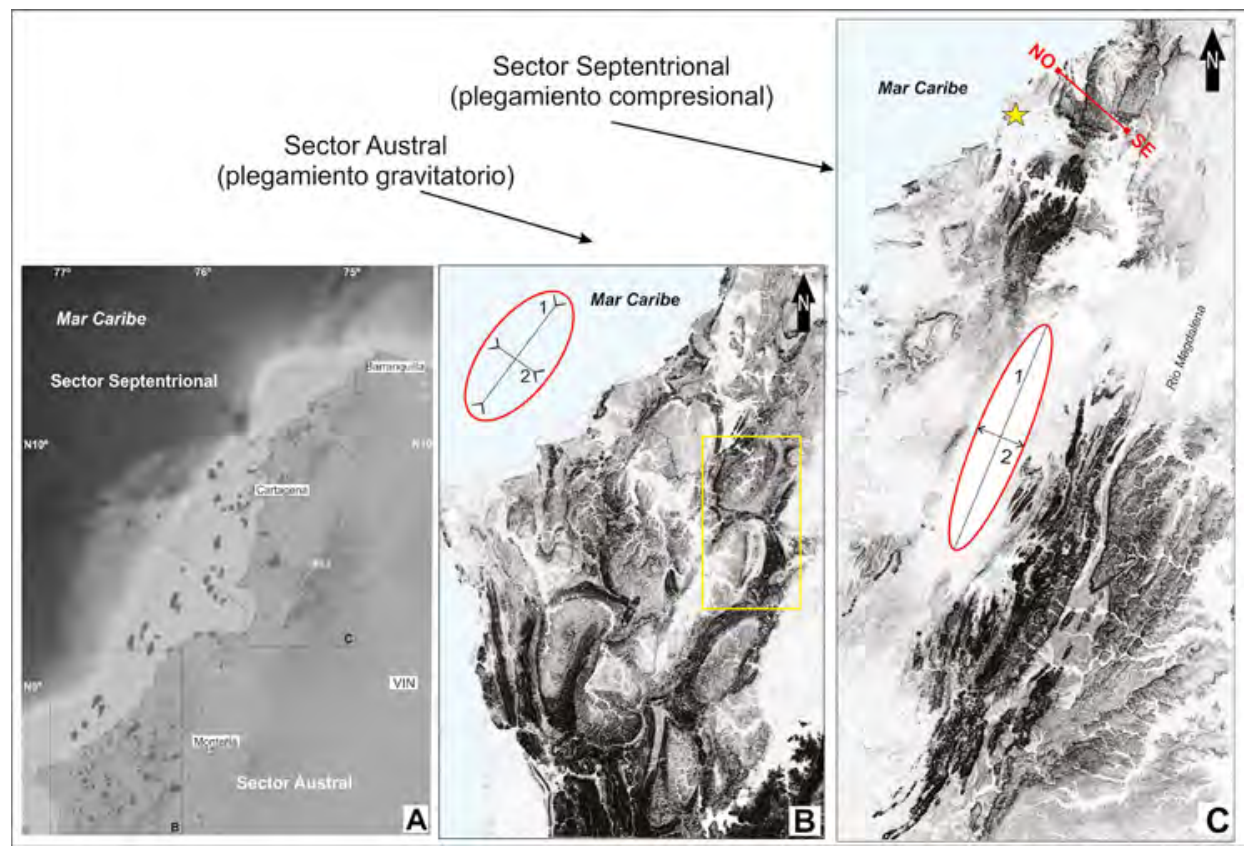

Figura 11. A. Distribución del diapirismo argilocinético sobre el MCC donde se expresan los diferentes tipos morfológicos de plegamientos asociados con el diapirismo. B. DEM del sector austral con pliegues gravitatorios, sinclinales muy extendidos y charnelas anticlinales apretadas (1: eje plegamiento; 2: ancho plegamiento). El rectángulo amarillo indica la localización de la Figura 16. C. DEM del sector septentrional con pliegues en échelon, con dobles buzamientos más apretados y con ejes más elongados. La estrella amarilla indica la localización del volcán Totumo, y la línea roja NO-SE indica la localización de la línea sísmica de la Figura 13. 


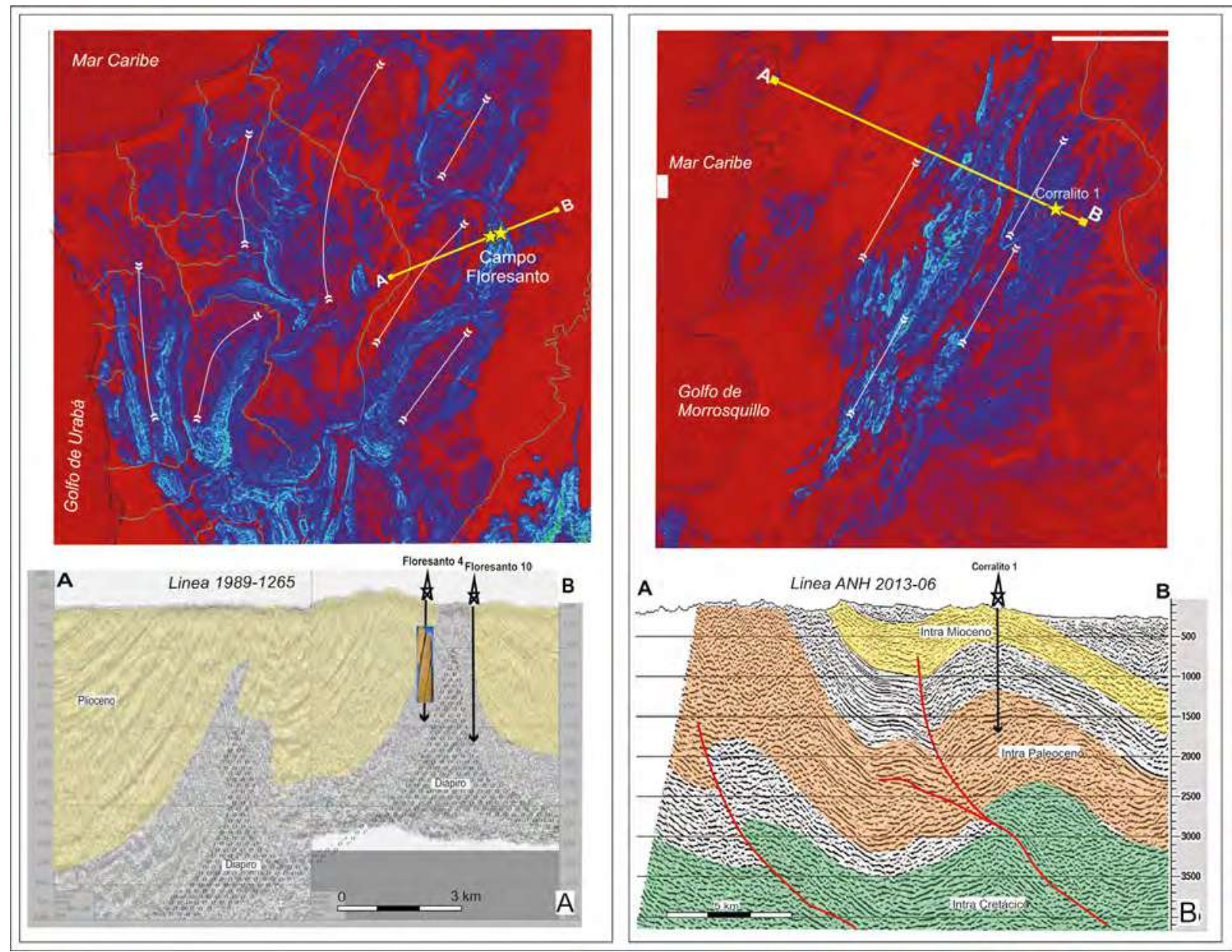

Figura 12. A. Modelo digital topográfico con una sección sísmica característica del sector austral del MCC, caracterizado por el Cinturón Sinú. Se aprecian plegamientos con anticlinales apretados ocupados por diapirismo (con los pozos Floresanto) y sinclinales amplios (localización en Figura 16). B. Modelo digital topográfico con una sección sísmica característica del sector central del MCC que incluye la porción al Cinturón San Jacinto. Se aprecian plegamientos con anticlinales y sinclinales más equivalentes y un diapirismo profundo.

Morales-Giraldo et al. (2017) identifican dos montículos sobre el fondo marino, asociados a diapiros de hasta 30 $\mathrm{m}$ de altura que pueden colonizar corales. García-Cortés et al. (2008) reconocen a partir de los foraminíferos planctónicos encontrados en los lodos expulsados en varios volcanes del MCC edades desde el Oligoceno Superior hasta el Mioceno superior - Plio-Pleistoceno. Sugieren que el diapirismo de lodo en el área está relacionado con las rocas fuente de esas edades; esta interpretación permite considerar que el emplazamiento del diapirismo de lodo y la continentalización, al menos de la cuenca del Sinú, podrían haber ocurrido después del Plioceno (Marín et al., 2010). La presencia de tres conjuntos de foraminíferos planctónicos de diferentes edades revela que las rocas fuente son tan antiguas como el Oligoceno superior, cuyo emplazamiento involucraba fragmentos de las rocas huésped de diferentes ciclos sedimentarios del Mioceno. A partir de estos datos cronológicos sugieren que: 1) los mecanismos de colocación de diapiros de lodo realizados después del ciclo sedimentario del Plio-Pleistoceno pudieron producir trampas de petróleo durante esta fase; 2) la presencia de tres conjuntos de foraminíferos planctónicos de diferentes edades revela que las rocas fuente son tan antiguas como el Oligoceno superior, cuyo emplazamiento involucraba fragmentos de las rocas huésped de diferentes ciclos sedimentarios del Mioceno.

En el sector comprendido entre el Golfo de Morrosquillo y Cartagena, el diapirismo está asociado con pliegues y fallamientos más compresionales, que exhibe en planta anticlinales y sinclinales más homogéneos con relaciones de largo (ejes del plegamiento) vs anchos muy disimiles, típicos de pliegues generados por una compresión horizontal (Figura 13). 
Cerca de la actual desembocadura del río Magdalena ocurren secuencias neógenas con fuertes tasas de sedimentación (Ercilla et al., 2002), se desarrollan pliegues en échelon con ejes más elongados y dobles buzamientos con diapirismo en niveles más profundos con morfologías que tienden a estrecharse hacia sus topes, al punto que terminan bloqueados por las secuencias que lo post-datan. Los lodos están constituidos por acumulaciones variables de arcillas y limos arcillo-arenosos de color gris oscuro a pardo con bloques embebidos $(5-80 \mathrm{~cm})$ de arcillolitas, limolitas, areniscas y caliza arrecifal (Herrera-Atencio y DíazMendoza, 2018). La presencia de estos bloques se debe a su arrastre por las erupciones en los volcanes de lodo y, en menor proporción, a las emanaciones de lodo que salen por las bocas o ventosas de los mismos.

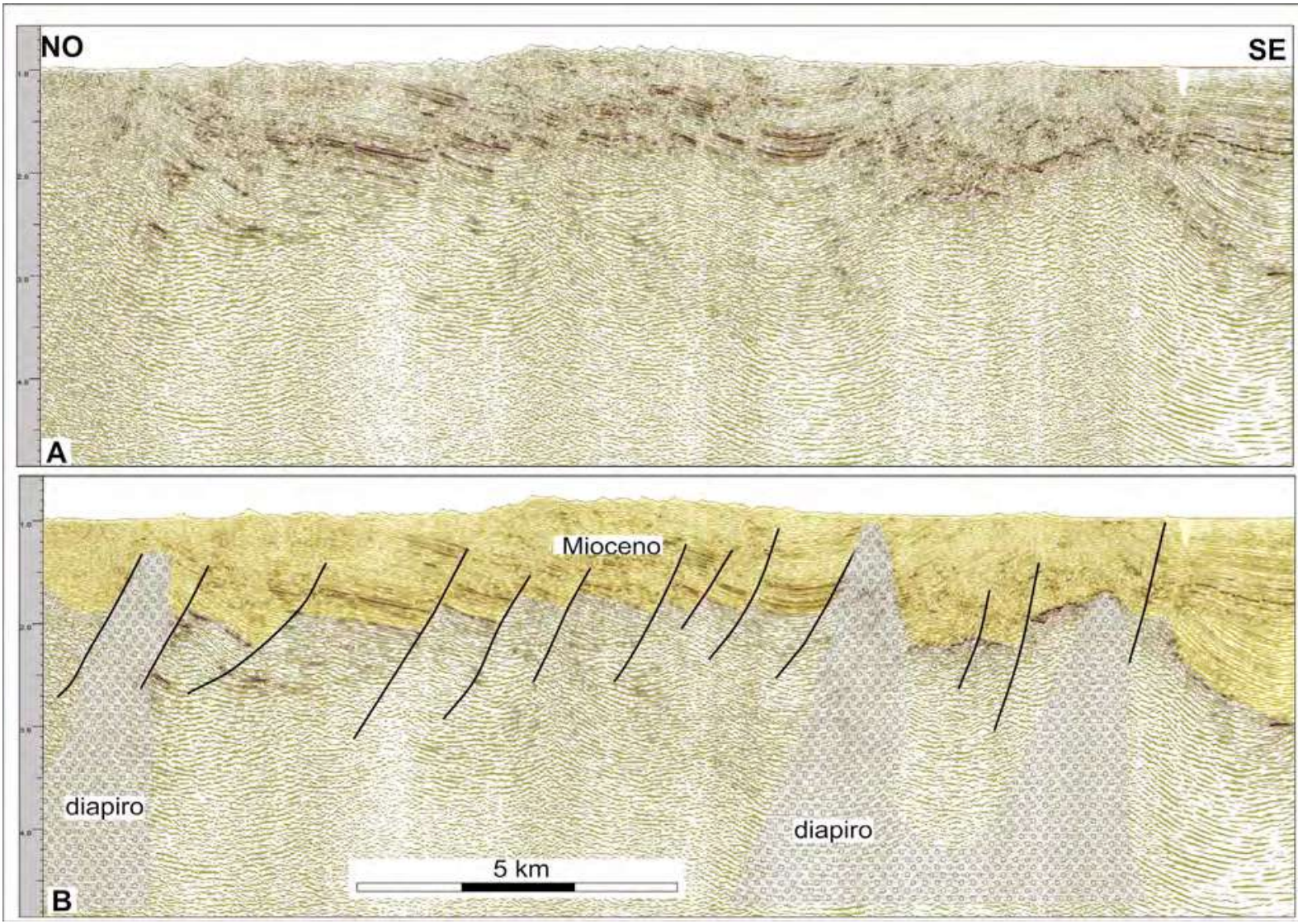

Figura 13. Sección sísmica A-1990-1450 característica de la región del MCC cercana a la desembocadura del río Magdalena que incluye la porción septentrional del Cinturón San Jacinto. Se aprecia un diapirismo que es progresivamente bloqueado por las secuencias suprayacentes y afectado por un fallamiento extensional con vergencia hacia el NO (véase localización en Figura $11 \mathrm{C})$.

El origen de los volúmenes lodosos extruidos durante las erupciones de los volcanes de lodo se asocia, acorde con la secuencia estratigráfica de la región, con los niveles arcillolíticos suprayacentes de edad OligocenoMioceno inferior. Sin embargo, en el proceso de ascenso de los materiales, arrastra también fragmentos de roca de secuencias encajantes, particularmente de areniscas, limolitas y arcillolitas, y muy localmente gravas. Herrera-Atencio y Díaz-Mendoza (2018) presentan, principalmente en la parte alta de los domos activos, lodos muy fluidos, con densidades unitarias que varían entre 1,4 y $1,7 \mathrm{~g} / \mathrm{cm}^{3}$; esta alta fluidez ha permitido que estos materiales una vez extruidos se hayan encauzado por drenajes naturales de la topografía actual. Shepard et al. (1968) describieron la presencia de volcanismo de lodo de hasta $1 \mathrm{~km}$ de diámetro en la zona del delta offshore del Magdalena, cuyos domos ascienden más de $200 \mathrm{~m}$ sobre la superficie del fondo del mar en profundidades de 900 a 1200 m.b.n.m., flanqueados por depresiones anulares cuyos estratos limitantes se disponen inclinados. El caso del volcán de lodo El Totumo es tal vez el más conocido desde 1794, con erupciones reportadas en los años 1839, 1848, 1925, 1943 y 1958 (Herrera-Atencio y DíazMendoza, 2018), además, por ser actualmente un objetivo turístico de la costa caribeña. Carvajal et al. 
(2010) lo describen con un diámetro aproximado de $1 \mathrm{~km}$ y unos $25 \mathrm{~m}$ de altura con respecto a las planicies circundantes, que exhibe en su tope una artesa de unos $30 \mathrm{~m}$ de diámetro con varias bocas decimétricas de emisión, y en su flanco oriental presenta un muy particular cono adventicio (gryphon) de unos $15 \mathrm{~m}$ de altura y un diámetro de $35 \mathrm{~m}$ donde los visitantes suelen introducirse en su cráter de 2 m (Figura 14).

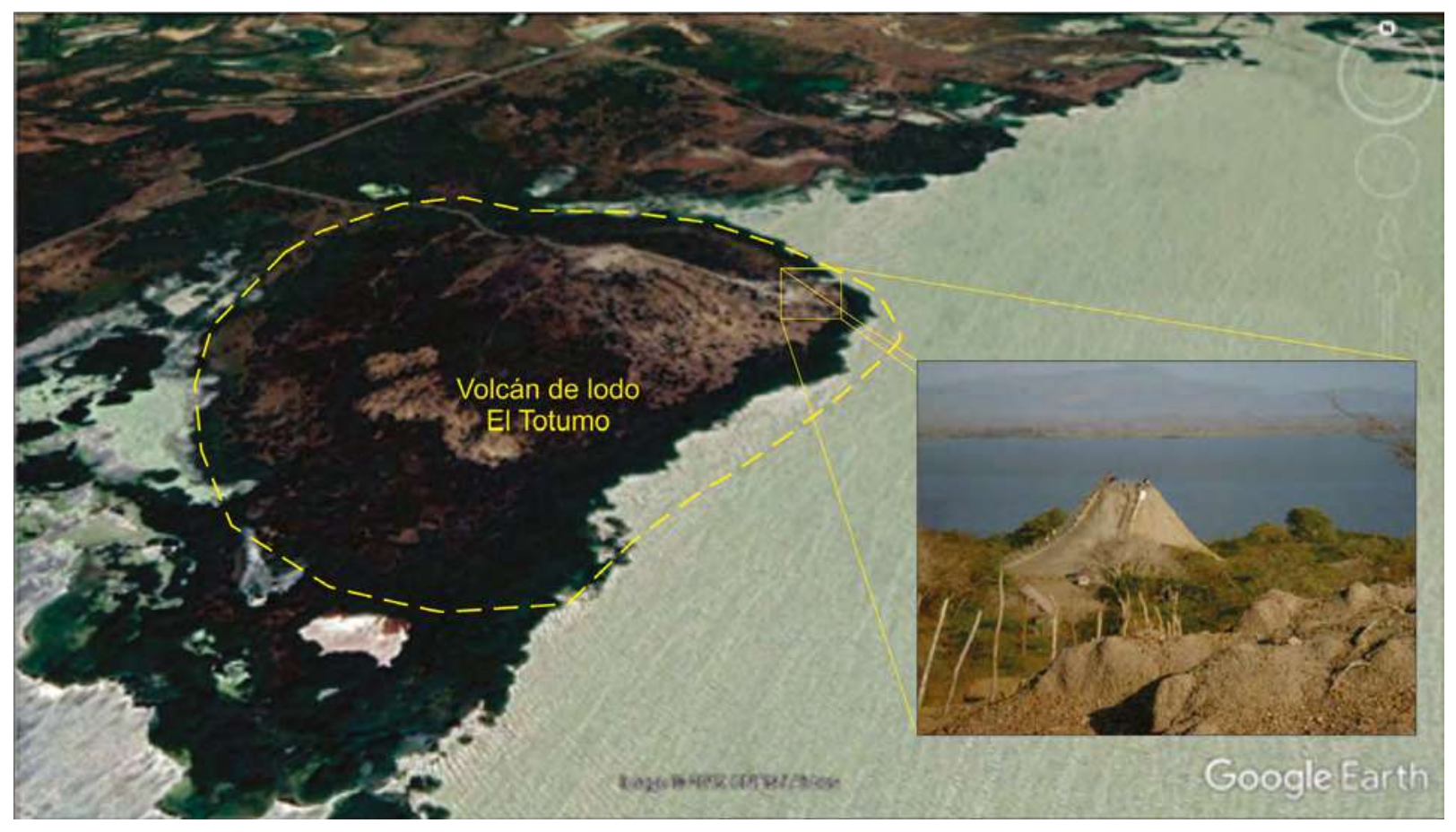

Figura 14. Imagen satelital del diapiro El Totumo (tomada en GoogleEarth con basculamiento hacia el norte), localizado muy

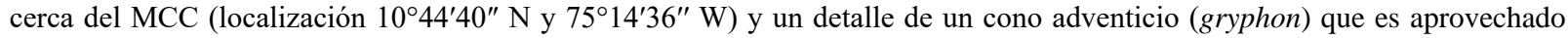
como atracción turística.

El volcán Totumo emana predominantemente arcillas tipo caolinita $(>40 \%)$ y esmectita $(10 \%-40 \%)$, y en menor proporción, en su orden clorita, illita, pirofilita, caolinita y bajos contenidos de esmectita con altos contenidos de cuarzo y bajos porcentajes de feldespatos, pirita, yeso y halita; en cambio, en otros diapiros las arcillas más frecuentes suelen ser de más de $40 \%$ esmectita y entre 10 y $20 \%$ de caolinita y gases constituidos por casi el 90\% de metano (Carvajal y Mendivelso, 2017; Herrera-Atencio y Díaz-Mendoza, 2018). Mineralógicamente, los lodos emanados a través de las bocas de los volcanes de lodo de la zona, se constituyen predominantemente de sílice, alúmina y menores proporciones de óxidos ferrosos, óxidos de calcio, potasio, calcio, magnesio, manganeso y titanio. Tal situación determina características físicas tales como humedades entre 1 y $2 \%$, pérdidas por calcinación en promedio entre 7 y 9 y un pH ácido entre 7 y 8 (Carvajal y Mendivelso, 2017). Sobre la costa, a la altura de Boca Tocino, aflora parcialmente un diapiro con composición más arenosa dentro de encajantes neógenos muy disturbados por la intrusión (Figura 15).

El diapirismo de lodo presente a lo largo del MCC, tanto en el onshore como el offshore, es uno de los fenómenos geológicos más particulares por su alta frecuencia (Carvajal, 2016) y por su asociación con los sistemas petroleros activos (Kopf, 2002; Dupré et al., 2008). La acumulación de potentes secuencias de limos y arcillas ricas en materia orgánica localizadas en su subsuelo favorece la sobrepresión de los fluidos intersticiales que promocionan su ascenso hacia la superficie a través del volcanismo de lodo (Briceño y Vernette, 1992; Carvajal et al., 2010).

Schamel et al. (1998), Aristizábal et al. (2009) y Quintero-Ramírez (2012), entre otros, han realizado estudios en el MCC debido a la importancia que tiene el diapirismo argilocinético como un mecanismo indicador de escape de hidrocarburos hacia zonas subaéreas. La geoquímica de los líquidos presentes 
puede revelar una migración compleja a partir de múltiples fuentes de fluidos (Dia et al., 1999; CastrecRouelle et al., 2002; Planke et al., 2003; Deville et al., 2006; Aguilera, 2011; Mora, 2018).

El antiguo campo hidrocarburífero Floresanto $\left(08^{\circ} 33^{\prime} 00^{\prime \prime} \mathrm{N}\right.$ y $\left.76^{\circ} 09^{\prime} 52^{\prime \prime} \mathrm{W}\right)$ es un buen ejemplo de asociación con un diapirismo de lodo que ocupa el núcleo del anticlinal apretado, que se dispone entre dos amplios sinclinales con geometrías de cubeta (Figura 16). Su descubrimiento en la década de los '40s se debió a métodos de mapeos de campo que reconocieron su cierre anticlinal, pero la mala calidad de los reservorios encontrados dentro del diapiro mostró una muy escasa producción que penalizó su continuidad a pesar de haberse producido algunos barriles de crudo.

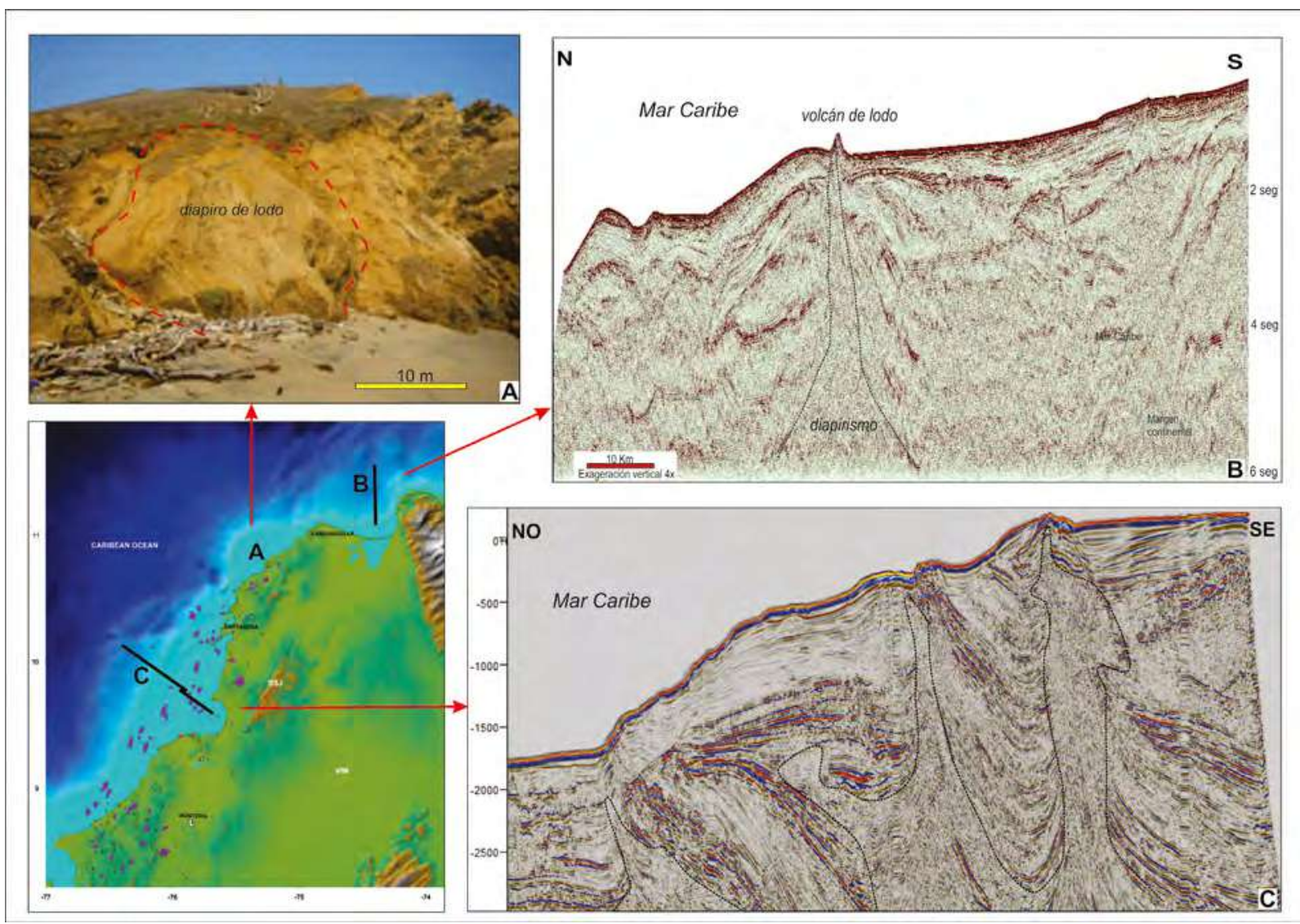

Figura 15. A. Afloramiento de diapiro emplazado en sedimentitas paleógenas de playa Boca Tocino (la barra indica unos 10 m). B. Línea sísmica 82-5100 que muestra un volcán de lodo sobre el lecho submarino. C. Línea sísmica (tomada de la ANH).

El nivel actual de la actividad exploratoria en el MCC no ha permitido cuantificar el enorme potencial de los recursos hidrocarburíferos y la evolución tectosedimentaria de las secuencias vinculadas con la definición de los sistemas petrolíferos que contiene. Los pozos exploratorios y los datos sísmicos de reflexión de calidad son todavía limitados para permitir una evaluación rigurosa de las secuencias sedimentarias de hasta más de $6000 \mathrm{~m}$ (Barrero et al., 2015). Sin embargo, la información disponible ha podido demostrar la existencia de numerosos estilos de trampas estructurales y estratigráficas con gran potencial, y el diapirismo argilocinético ha comprobado la generación de hidrocarburos al exponerlos en superficie, permitiendo evaluar sus características geoquímicas (García-González et al., 2019; González-Morales et al., 2015). 

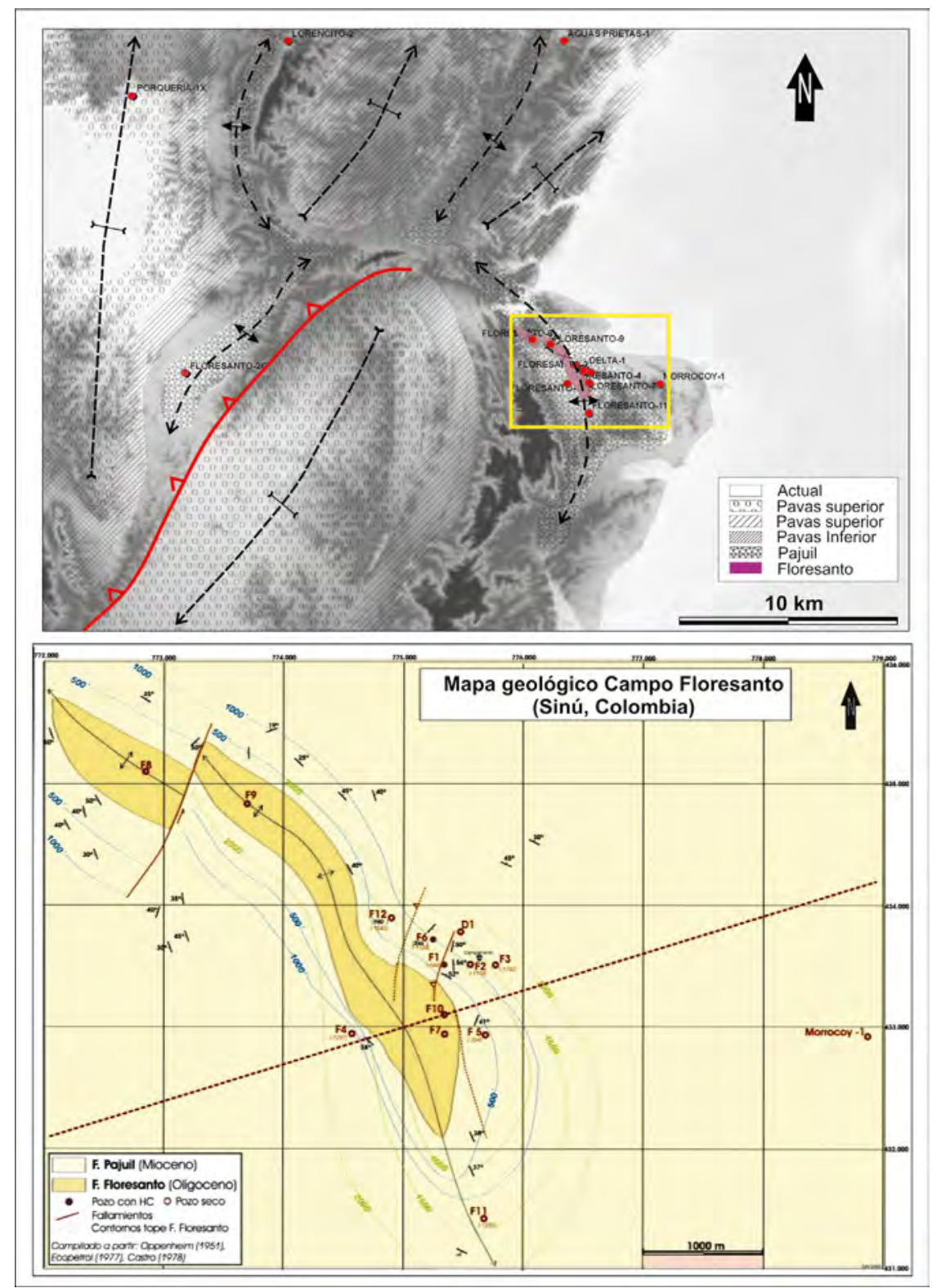

Figura 16. Bosquejos geológicos del sector del Campo Floresanto (véase ubicación en Figura 11B). A. Modelo digital topográfico con la expresión de plegamientos gravitatorios de amplias cubetas sinclinales adyacentes a anticlinales apretados asociados con diapirismos. B. Esquema estructural y localización de los pozos exploratorios (tomado de Oppenheim, 1957). La línea punteada indica la ubicación de la línea sísmica de la Figura 12A.

\section{Discusión}

\section{Relaciones tectosedimentarias}

Concomitantemente con el desarrollo de la sedimentación a lo largo del MCC, el escenario tectónico fue igualmente variando desde uno típicamente extensional hasta uno compresional, relacionado con la convergencia oblicua entre las placas Sudamérica y Caribe, según una dirección general de esfuerzo principal máximo dispuesto
WNW-ESE (Taboada et al., 2000; Horton, 2018). Este cambio habría tenido lugar a partir del Mioceno, aunque no fue aún lo suficientemente intenso como para exhibir las características propias de una típica subducción, como fue mencionado previamente. Como consecuencia del escenario tectónico reciente, el MCC exhibe una deformación regional con evidencias de componentes transcurrentes dextrales, contemporánea con la sedimentación que se sobreimpone invirtiendo variablemente las estructuras extensionales sinsedimentarias previas. 
A partir del análisis dinámico y combinado entre la deformación y la sedimentación, es posible identificar a lo largo del MCC la interacción de factores i) depositacionales que transportan y depositan volúmenes sedimentarios, que hacen progresar hacia el norte la influencia del crecimiento continental sobre la placa oceánica Caribe, y ii) factores deformacionales que producen variaciones de los niveles de base para favorecer subsidencias en los depocentros, somerizaciones y exhumaciones de los altos que los segmentan. Relacionado con esta dinámica tectosedimentaria, Gómez et al. (2005) presentan una reconstrucción paleoambiental de las terrazas marinas bajas al norte de Cartagena, basados en datos radiométricos de Bürgl (1965) y en las reconstrucciones paleogeográficas de Duque-Caro (1990) y Burel (1982). Estos trabajos permiten establecer la existencia de bajas tasas de sedimentación, asociadas con tasas relativamente altas de levantamiento del borde costero ( $\pm 3,4 \mathrm{~mm} / \mathrm{año})$.

El mecanismo ascendente de numerosos diapirismos argilocinéticos localizados tanto mar adentro como sobre el continente moviliza hacia la superficie fragmentos de rocas y fluidos intersticiales en forma de agua, gas y, a veces, petróleo. De este modo, exponen en la superficie características geológicas directas de secuencias sepultadas en áreas aún desconocidas e inaccesibles por la ausencia o incipientes coberturas exploratorias. Así, pueden proveer evidencias muy valiosas de presencias en el subsuelo de potenciales recursos de hidrocarburos y/o de hidratos de carbono y aportan datos petrofísicos de las secuencias atravesadas. El estudio directo de fragmentos de rocas incorporados desde las paredes de sus encajantes y arrastrados por el diapirismo constituye una forma de cuttings que contribuye con el conocimiento de la estratigrafía local; también, puede determinar las características de la porosidad y permeabilidad de posibles rocas reservorio. De este modo, suelen ser esenciales para demostrar la presencia de los elementos básicos de un sistema petrolífero y analizar la naturaleza de los hidrocarburos asociados. Además, permite determinar la presencia de roca madre, composición, grado de madurez y las posibilidades de los mecanismos de carga (Link, 1952; Hedberg, 1974; Reed et al., 1990; Dia et al., 1999; Graham y Pepper, 2008; Etiope et al., 2009; Niemann y Boetius, 2010; Tinivella y Giustiniani, 2013). Sin embargo, el estudio de las emanaciones fluidas y sólidas superficiales aportadas por el diapirismo, sin la ayuda de datos complementarios proporcionados por relevamientos sísmicos y/o pozos exploratorios, no es suficiente para predecir la capacidad de retención que pueden ofrecer los volúmenes diapíricos.

En el caso del MCC no se tiene aún conocimiento detallado de la estratigrafía de los niveles pelíticos donde se genera el diapirismo, debido a que se reconocen múltiples evidencias de la presencia de buenos horizontes contenidos desde el Cretácico (Formación Cansona) hasta el Neógeno (formaciones Floresanto, Tubarao, Porquero, etc.). La información disponible de subsuelo a lo largo del MCC resulta aún insuficiente para poder identificar con mayor precisión alguno de los horizontes responsables, que incluso podrían ser varios, que contribuyan con el desarrollo de un mismo proceso argilocinético.

\section{Contribución al conocimiento del potencial hidrocarburífero del MCC}

El conocimiento de los volcanes de lodoy manaderos con gases bacteriales está restringido a la porción austral del Sinú Atlántico, donde se presentan grandes espesores de sedimentos jóvenes. Los gases, salvo muy pocas excepciones, están compuestos predominantemente por metano con bajos contenidos de $\mathrm{C}_{2}, \mathrm{C}_{4}$ y $\mathrm{CO}_{2}$. La variabilidad isotópica de los diferentes grupos confirma distintos procesos formadores de gas en el subsuelo, con rangos de bacteriogénesis que varían desde baja a alta temperatura. De este modo, se puede considerar que mezclas de gases de origen termogénico y bacterial (posiblemente mezcla de Grupos 1 y 3) se encuentran en las áreas más costeras septentrionales; gases de origen termogénico (Grupo 3) están restringidos predominantemente en áreas norteñas del Sinú-San Jacinto (Beeunas et al., 1991). Gracia et al. (2012) identifican en muestreos del fondo marino del MCC muchas especies de bivalvos, típicamente asociados con condiciones reductoras, que sugieren su desarrollo por manaderos de metano provenientes del diapirismo argilocinético. Aguilera (2011) calculó valores de temperatura dentro de la subcuenca SinúSan Jacinto que determinan rangos desde inmaduros hasta condiciones de sobremaduración $\left(370-493^{\circ} \mathrm{C}\right)$. Para la Formación Cansona estimó, a través de la vitrinita $(\%$ Ro $=0,77)$, valores de Tmax que fluctúan desde 438 a $453^{\circ} \mathrm{C}$, mientras que para los sedimentos depositados durante el Cenozoico, los valores de Tmax no superan los $440^{\circ} \mathrm{C}$ y $\%$ Ro de 0,63 , lo que comprueba el inicio de la ventana de generación de hidrocarburos. García-González et al. (2019), basados en análisis de gas, condensados y bacterias encontradas en el volcán de lodo de Arboletes, indican que los 
gases biogénicos extraídos han sido biodegradados a petróleo (Figura 17). Además, aportan información valiosa sobre el impacto en la estabilidad de las operaciones de perforación e instalación de facilidades y de emisión de metano hacia la hidrósfera y atmósfera que contribuye con el efecto invernadero del cambio climático.

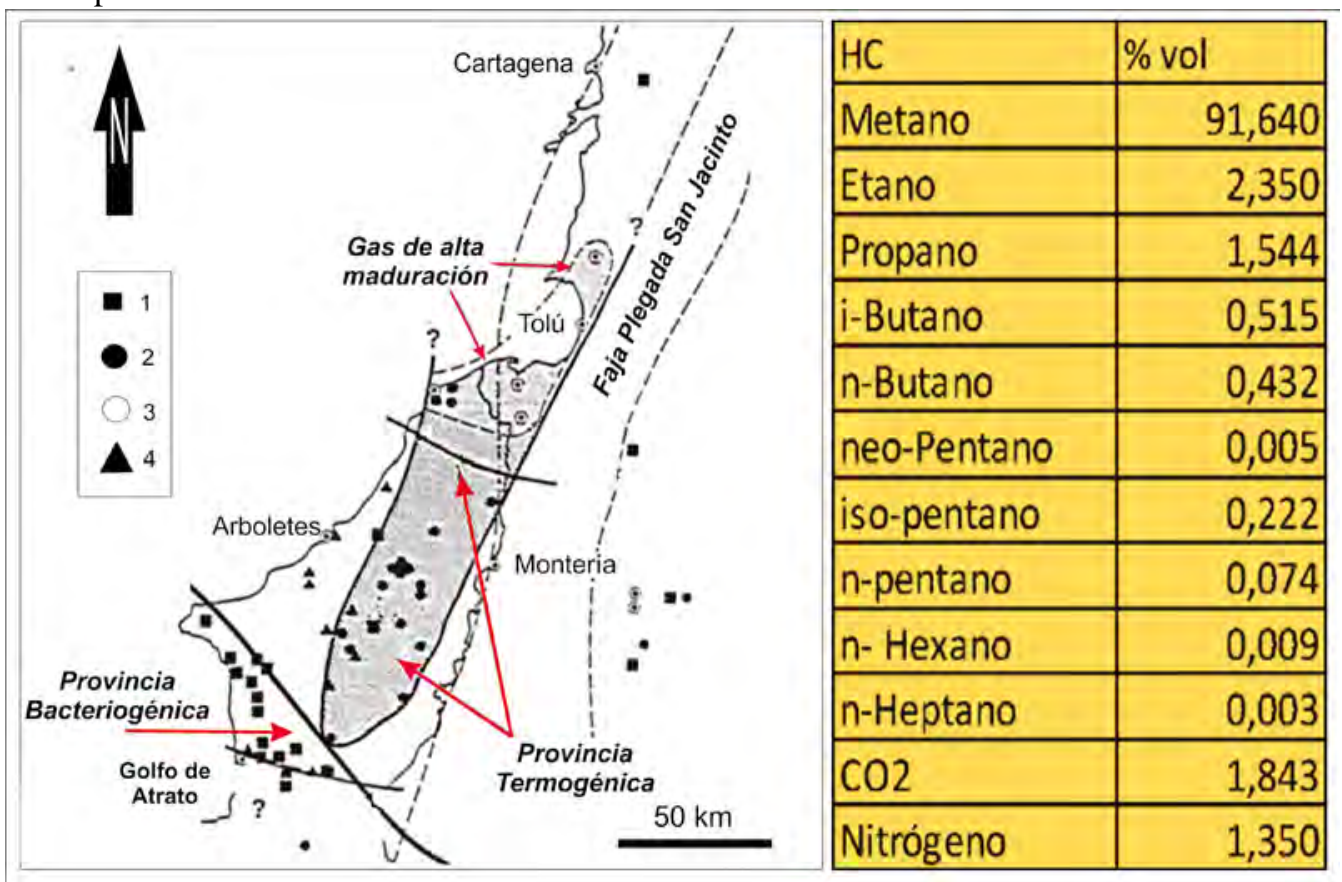

Figura 17. Distribución regional de muestreos geoquímicos de gases biogénicos (1), termogénicos (2), de fuentes de alta maduración (3) y mixtos (4), obtenidos de volcanes de lodo. Los datos de la tabla muestran la composición de los fluidos extraídos en el volcán Arboletes (modificado de García-González et al. 2019).

\section{Oportunidades exploratorias de hidrocarburos en el MCC}

Mediante el análisis integral de la información de superficie y subsuelo, generada por actividades exploratorias de las últimas décadas, apoyadas por los condicionantes tectosedimentarios descriptos, se sugiere un modelo evolutivo interpretativo que contribuye con la visualización del control del emplazamiento de oportunidades exploratorias de hidrocarburos asociadas al desarrollo de diapirismo en el MCC (Figura 18).

A partir de la depositación de los niveles (desde secuencias tanto cretácicas como paleógenas) donde se produce la maduración de sus contenidos orgánicos (Figura 18A), comienza su subsidencia por la acumulación de las secuencias que lo sepultan (Figura 18B), y se genera la migración de los fluidos hacia las charnelas de los anticlinales apretados, que son ocupadas por el diapirismo (Figura 18C). El material pelítico infrayacente de los sinclinales es escurrido y movilizado por el mayor peso de las secuencias que lo ocupan y lo extraen hacia la superficie como volcanes de lodo acompañados de emanaciones de hidrocarburos. Simultáneamente, se desarrollan fallamientos compresionales y extensionales que pueden aprovechar discontinuidades basamentales (Figura 18D). Estas estructuras compartimentalizan los altos estructurales contribuyendo con el acomodamiento de los sucesivos rellenos sedimentarios que tienden a apilarse progresivamente sobre los sectores más profundos. Así, las mejores facies con capacidad de reservorio resultarán desplazadas de los altos estructurales hacia sus flancos, donde las secuencias de crecimiento tienden a desarrollar traslapamientos (Figura 18E). Este modelo considera que la mejor localización de objetivos exploratorios se dispone en los flancos anticlinales por i) el eficiente entrampamiento de hidrocarburos que puede representar la migración de fluidos provenientes de los ambientes generadores en las zonas más profundas soterradas en los sinclinales y ii) por la posibilidad de exhibir niveles más areniscosos con mejores propiedades de reservorio. 


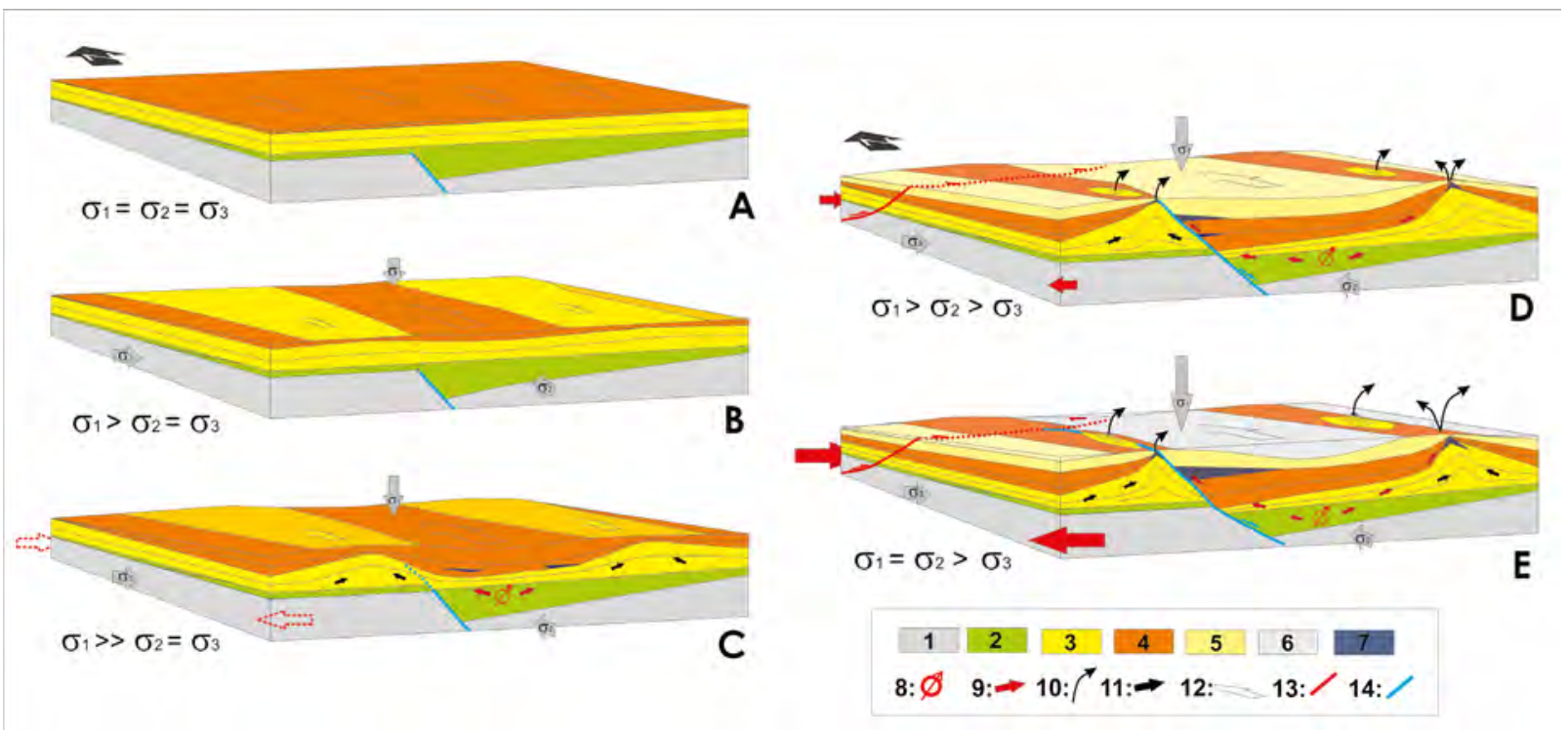

Figura 18. Modelo prospectivo esquemático de hidrocarburos basado en la evolución del diapirismo de lodo sobre la porción austral del MCC, asociado con la progradación de las secuencias terciarias suprayacentes. 1: basamento técnico, 2: Cretácico, 3: Paleógeno, 4: Mioceno, 5: Plioceno, 6: Cuaternario, 7: acumulación de hidrocarburos, 8: cocina, 9: migración de hidrocarburos, 10: emanación de fluidos por diapirismo-volcanes de lodo, 11: flujo diapírico, 12: progradación de la sedimentación hacia el norte, 13: fallamiento sinsedimentario compresional y 14: fallamiento sinsedimentario extensional.

\section{Rasgos del diapirismo argilocinético en la interpretación sísmica}

Los volúmenes argilocinéticos están constituidos por materiales de poca cohesión, arcillas, agua, salmueras, hidrocarburos y lodos de más baja densidad que las secuencias sedimentarias adyacentes, por lo que este material es típicamente reconocido como un intervalo de baja velocidad, representado por facies sísmicas más transparentes y de bajas amplitudes (Musgrave y Hicks, 1968; MacDonald et al., 2000; Milkov, 2000; Mourad, 2005; Istadi et al., 2012). El análisis de los contenidos de frecuencia de los datos sísmicos puede ayudar a identificar el gas libre en los sedimentos, porque absorbe el componente de alta frecuencia de la energía sísmica (Shipley et al., 1979; Taylor et al., 2000; Wagner-Friedrichs et al., 2008). La disminución abrupta de las frecuencias principales de aproximadamente $115 \mathrm{~Hz}$ por encima de los puntos brillantes a $95 \mathrm{~Hz}$ por debajo dentro de un rango de $50 \mathrm{~m}$ apoya la presencia de gas libre.

Si bien, tanto el diapirismo halocinético como el argilocinético comparten rasgos morfoestructurales, las características propias de los materiales involucrados difieren en los relevamientos sísmicos (Figura 19). Las diferencias se relacionan con las velocidades de transmisión sónica, las conductividades térmica y eléctrica, la resistencia mecánica y las características de acumulaciones residuales que suelen encontrarse sobre sus porciones cuspidales (cap rocks). A partir de estas diferencias pueden reconocerse diapiros generados en niveles fuentes, depositados en ambientes restringidos y desérticos (evaporíticos) o en condiciones más acuosas y turbidíticas (pelitas).

Mazzini et al. (2009) consideran una relación íntima significativa entre los volcanes de lodo, las acumulaciones de hidrocarburos y las trampas estructurales que determinan, por ejemplo, anticlinales; además, por sus características lodosas se reconoce la capacidad sellante de los mismos. Los canales de alimentación para los volcanes de lodo, normalmente enraizados por debajo de los niveles del reservorio (comúnmente a 1-3 km de profundidad), pueden actuar como vías para los fluidos durante las erupciones o en los episodios inactivos (Planke et al., 2003; Milkov, 2005). 


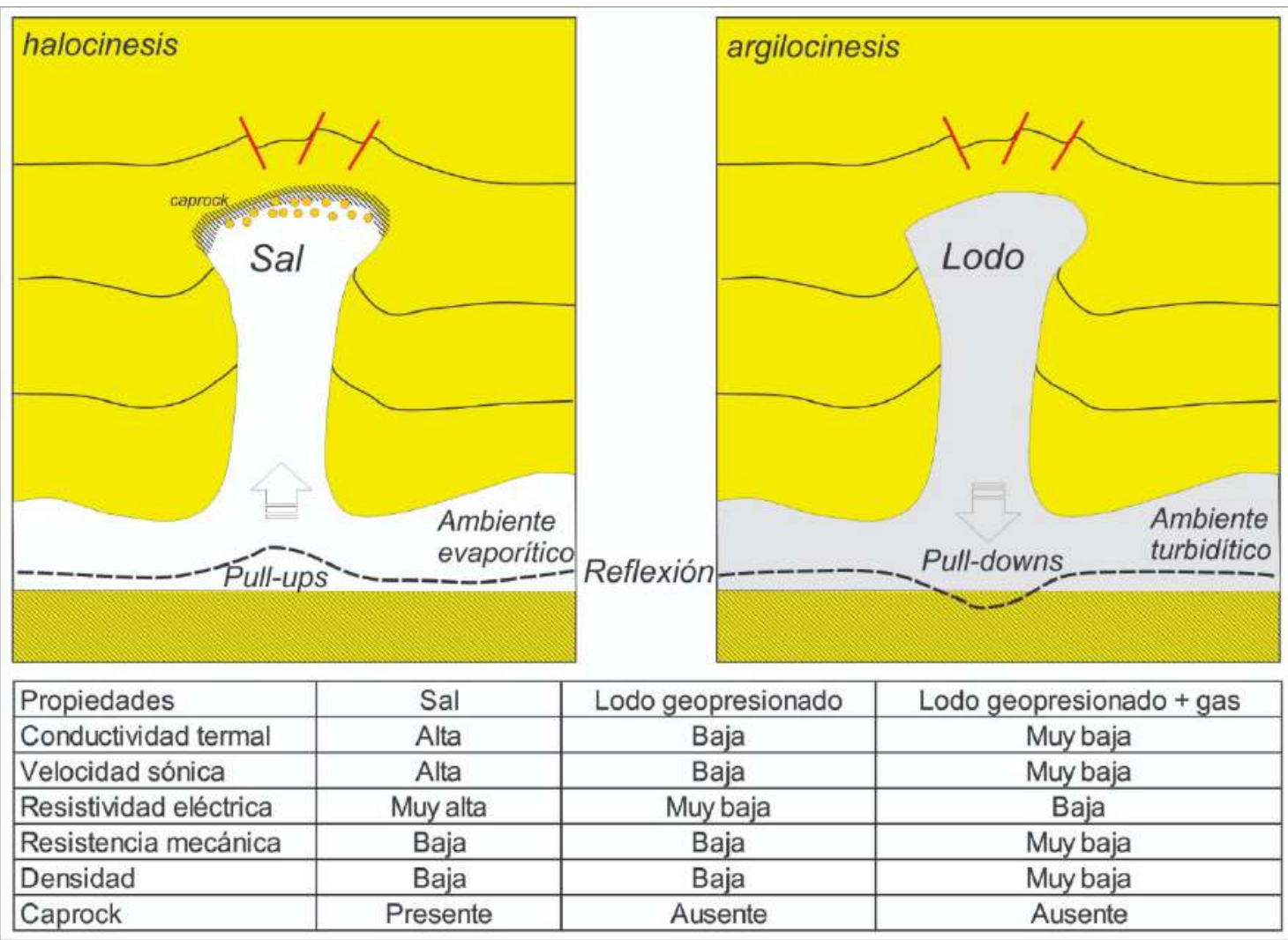

Figura 19. Esquema comparativo de algunas propiedades características diferenciales del diapirismo argilocinético y halocinético, sugeridas por los relevamientos sísmicos.

\section{Consecuencias ambientales del diapirismo argilocinético}

El diapirismo de lodo es un menospreciado fenómeno natural que interfiere en el ciclo del carbono, ya que libera grandes cantidades de este a la hidrósfera y a la atmósfera (Kopf, 2003; Etiope y Milkov, 2004; Foucher et al., 2010; MacDonald et al., 2000; Mazzini et al., 2009; Milkov, 2000; Niemann et al., 2006). Conjuntamente con la descarga de los característicos sedimentos fluidizados, el volcanismo de lodo es una de las fuentes naturales más importantes de emisión dominada por el gas metano, que contribuye al aporte moderno de metano atmosférico al efecto invernadero, con cantidades anuales de hasta 6 a 9 Mt (Dimitrov, 2002; Milkov, 2000, 2005; Kopf, 2002, 2003; Etiope y Milkov, 2004; Graham y Pepper, 2008).

Las amenazas asociadas a estos fenómenos pueden ser relacionadas también con efectos catastróficos por la extrusión violenta delodos efusivos semilíquidos y caída de bloques, emisión de gases inflamables e incendios, ondas de choque por los estruendos y fracturamiento y modificaciones del terreno circundante (Dimitrov, 2002; Milkov, 2000, 2005; Tingay et al., 2018). Los terremotos pueden desencadenar la erupción de lodo en forma de volcanes (Davies et al., 2007, 2008). Bonini et al. (2016) analizaron erupciones asociadas con la producción de hidrocarburos en Azerbaiyán, Italia, Rumania, Japón, las Islas Andamán, Pakistán, Taiwán, Indonesia y California para investigar la naturaleza de los cambios de estrés que inducen nuevas erupciones y modulan las erupciones en curso.

Se considera que las erupciones pueden canalizarse como un reventón o descontrol del fluido de formación que accede desde el reservorio hacia una formación de baja presión en el pozo y finalmente rompe la superficie (Tingay et al., 2008, 2018; Sawolo et al., 2009, 2010). Incluso, se describe la generación de microsismicidad y la actividad cíclica del volcanismo de lodos (Mellors et al., 2007; Deville y Guerlais, 2009; Manga y Brodsky, 2006; Manga et al., 2009; Istadi et al., 2009; Bonini et al., 2016). En zonas marinas, la amenaza ambiental se asocia igualmente con los cambios batimétricos que pueden generar concentración de la energía del oleaje en determinados sitios de la costa, ocasionando erosión y la aparición de islas localmente acompañadas con manifestaciones de fuego (Foucher et al., 2010). 
Kerr et al. (1970) reportan erupciones semejantes en la región occidental de Chatham, en la isla Trinidad, donde la extrusión que generó islas estuvo acompañada de gas que entró en ignición y explotó violentamente.

En la región estudiada del MCC se registran numerosos fenómenos catastróficos vinculados con el diapirismo argilocinético. Carvajal et al. (2010) y Carvajal (2016) mencionan que los primeros registros conocidos de fenómenos de impacto ambiental por el volcanismo de lodo en el litoral caribeño de Colombia fueron recopilados por el padre Jesús E. Ramírez en 1979 en su obra "El volcán submarino de Galerazamba". Este volcán, localizado a pocos kilómetros al oeste del volcán Totumo, ha tenido un registro histórico de varias explosiones con escape de gases, que al contacto con la atmósfera se incendian y han sido vistos desde tierra por los habitantes del lugar. La última manifestación sucedió el 27 de diciembre de 1991 y ha ocurrido de manera recurrente cada 18 o 20 años. El 27 de abril del 1999 la erupción del volcán de Pueblo Nuevo arrojó aproximadamente $60.000 \mathrm{~m}^{3}$ de lodos canalizados parcialmente por un drenaje noroccidental. Meses más tarde, el 23 de agosto del 2000, el volcán Totumo hizo erupción y arrojó aproximadamente $35.000 \mathrm{~m}^{3}$ de lodos que ocasionaron la obstrucción de la carretera de acceso a la boca del cono adventicio (gryphon) del mismo nombre, conocido por su atractivo turístico (Figura 14). Duque-Caro y Guzmán (1991, en Carvajal et al., 2010) informan que durante el evento de octubre de 1976, por las bocas el Cocuyo y San Diego del volcán de lodo de la Lorenza (departamento de Córdoba), ocurrieron erupciones explosivas y llamas que generaron la pérdida de varios animales y el enterramiento por lodo de una casa. Luego, el 9 de marzo de 1992, en un área cercana, otra erupción violenta de lodos y gases dañó pastizales en un diámetro cercano a los $600 \mathrm{~m}$ y ocasionó quemaduras de segundo grado en un infante lugareño. En total, la erupción de unos $80.000 \mathrm{~m}^{3}$ de lodo fueron acumulados en una colada de $200 \mathrm{~m}$ de diámetro y 2,5 m de altura, asociados con incendios que se extendieron $300 \mathrm{~m}$ al sureste de la zona de emisión. Correa (1998) menciona la generación de una isla debido a la erupción de material lodoso frente a las costas de la población de Punta Canoas (a unos 20 km al norte de Cartagena), ocurrida en el mes de diciembre de 1979, que duró varios días en desaparecer luego por efecto de la erosión marina imperante, coincidente con el terremoto de Tumaco. Cadavid y Rico (1992) informan la aparición de una isla frente a las costas de Damaquiel (en San Juan de Urabá, Antioquia), asociada con un sismo cuyo epicentro se localizó en la región de Murindó; este evento se vinculó con la erupción del volcán Cacahual durante el 17 y 18 de octubre del 1992 y produjo sismos e incendios que dejaron 9 víctimas fatales (Martínez et al., 1994). También, reportes de prensa colombianos (e.g. El Tiempo y El Espectador) mencionan erupciones recientes (últimos 6 meses) de diapiros de lodo en la región de Necoclí (Golfo de Urabá), que implican riesgos graves para los pobladores, e incluso han obligado a sus relocalizaciones. Estos fenómenos asociados de diapirismo de lodo y sismicidad producen una inestabilidad morfológica del litoral que se manifiesta en cambios de línea de costa, variaciones topográficas y amenazas geológicas que obligan a constantes modificaciones de los emplazamientos antrópicos (Velázquez, 2005; Correa et al., 2007; Restrepo et al., 2007; Ojeda et al., 2007).

Debido a las consecuencias catastróficas de los procesos diapíricos, Carvajal et al. (2010) realizan una zonificación geotécnica del volcán de lodo del sureste de Cartagena, con la finalidad de evaluar las características dinámicas y los impactos ambientales que exhibe el diapirismo de lodo en la región. Complementariamente, Herrera-Atencio y DíazMendoza (2018) definen sobre el MCC zonas con susceptibilidades vinculadas con posibles amenazas o factores de riesgo de suelos para algunas actividades antrópicas, como fenómenos de erosión y desertización de suelos, que los hace no aptos para construcción y otros usos estructurales.

\section{Conclusiones}

El Margen Caribeño Colombiano presenta gran cantidad de ocurrencias de diapirismo argilocinético, expresadas en superficie por volcanes, coladas y emanaciones de lodo, y en el subsuelo por volúmenes diapíricos identificados a partir de la interpretación de los relevamientos sísmicos relacionados con la exploración de hidrocarburos. Los fenómenos de diapirismo se disparan fundamentalmente por la inestabilidad gravitatoria que determina la menor densidad de los materiales movilizados con respecto a las secuencias que lo suprayacen. La presencia de fracturas o zonas de debilidad y las presiones debidas al soterramiento facilitan la estimulación de sus mecanismos ascendentes.

Los volúmenes argilocinéticos constituyentes de los fenómenos diapíricos se originan a partir de secuencias sedimentarias turbidíticas (Cretácico-Cenozoicas) con niveles pelíticos y fluidos asociados, suprayacidos por acumulaciones neógenas potentes, vinculadas con la 
progradación y expansión septentrional del margen continental. Este escenario tectónico, caracterizado por esfuerzos compresionales verticales, corresponde a un contexto preferencialmente gravitatorio extensional de margen pasivo del MCC, favorecido por los grandes aportes sedimentarios neógenos transportados desde las áreas de aporte cordilleranas que progresivamente trasladan la costa hacia el norte y nuclean los característicos deslizamientos submarinos.

El diapirismo argilocinético involucra niveles silicoclásticos finos (limos y/o arcillas) con importantes contenidos acuosos adquiridos durante su depositación, y que no pudieron ser oportunamente expulsados durante el soterramiento por la rápida disposición de niveles suprayacentes sellantes. Los niveles generadores suelen contribuir con la fluidalidad al aportar fluidos hidrocarburíferos, debido a la maduración de sus contenidos orgánicos. Por esta razón, la argilocinesis es también un buen indicador, cuando aún no se dispone de las metodologías exploratorias tradicionales del subsuelo, de la presencia y las condiciones petrofísicas del sistema petrolífero asociado, por el aporte al conocimiento de las litologías del subsuelo a través de los clastos que transportan.

Las manifestaciones morfológicas del diapirismo de lodos están básicamente condicionadas por las relaciones entre las tasas de sedimentación de las secuencias suprayacentes con respecto a las velocidades de ascenso del diapiro. Si la tasa de sedimentación es baja, el diapirismo progresa expandiéndose de tal forma que puede alcanzar la superficie y formar volcán de lodo y coladas; contrariamente, si es potente el diapirismo, se atenuará hasta su posible total bloqueo.

Se identifica una distribución regional del diapirismo a partir de las características tectosedimentarias condicionantes del MCC. En la porción austral (Cinturón Sinú), donde las tasas de sedimentación son más débiles por pérdida de los aportes del paleo río Cauca, se favorece preferencialmente el desarrollo de una mayor actividad diapírica moderna. En cambio, en la porción septentrional (Cinturón San Jacinto), donde la exhumación del cinturón Sinú-San Jacinto determinó que la carga sedimentaria del paleo río Cauca confluyera hacia el río Magdalena, ocurre una atenuación y bloqueo del diapirismo por las mayores tasas de sedimentación.

La presencia del diapirismo argilocinético del MCC ha impactado variablemente en las actividades exploratorias de hidrocarburos, a partir de la generación de objetivos basados en la interpretación sísmica con buenas geometrías de trampas. Sin embargo, los consiguientes pozos exploratorios comprobaron en estos objetivos propiedades de los reservorios encontrados escasamente. Por esta razón, el MCC exhibe un potencial vigente por su indudable generación de hidrocarburos a partir de las manifestaciones superficiales y de las evidencias obtenidas en pozos de su larga historia exploratoria. Por ello, se justifica continuar con la identificación de nuevos objetivos mediante actividades exploratorias concentradas en las zonas de flancos de los altos estructurales asociados con el diapirismo. De esta manera, se podrán balancear las óptimas propiedades de los cierres estructurales con las mejores calidades de almacenamiento de las secuencias más areniscosas que los post-datan.

Finalmente, los fenómenos de ascenso y extrusión de los volúmenes argilocinéticos han sido tan rápidos y violentos que en numerosos casos pueden producir eventos catastróficos en las actividades antrópicas y condiciones ambientales de las superficies que afectan. Incluso, pueden alterar las características geomecánicas de las instalaciones relacionadas con las actividades exploratorias y productivas. Por estas razones, su estudio y monitoreo preventivo es más que pertinente.

\section{Agradecimientos}

Se desea dejar constancia de nuestro agradecimiento a los colegas integrantes del Finding Team Colombia de Repsol durante las actividades exploratorias del MCC que contribuyeron con información de subsuelo y aportaron discusiones fructíferas relacionadas con la problemática del diapirismo y la potencialidad de sus oportunidades exploratorias. Los colegas Iván D. Correa A. (EAFIT) e Iván D. Olaya López (Mansarovar Energy) aportaron constructivos y generosos comentarios que clarificaron y complementaron el trabajo.

\section{Referencias}

Aguilera, R. (2011). Geology and hydrocarbon potential Sinú and San Jacinto basins. In: F. Cediel, G.Y. Ojeda, F. Colmenares (eds.). Petroleum geology of Colombia. Vol. 12. Agencia Nacional de Hidrocarburos.

Akhmanov, G.G.; Mazzini, A. (2007). Mud volcanism in elisional basin. International Geological Workshop on Sidoarjo Mud Volcano, Jakarta, Indonesia. 
Alfaro, E.; Barrera, D.F.; Rossello, E.A. (2013). Diachronic Cenozoic wrenching in the southwest Colombian Basin. Comunicações Geológicas, 100(1), 55-65.

Ali-Zade, A.; Shnyokov, E.; Grigorianz, B.; Aliev, A.; Rahmanov, R. (1984). Geotectonic conditions of mud volcano manifestation on the Earth and their significance for oil and gas prospects. 27th World Geological Congress Proceedings. C13: 166-172 (in Russian).

Aristizábal, C.O.; Ferrari, A.; Silva, C. (2009). Control neotectónico del diapirismo de lodo en la región de Cartagena, Colombia. Ingeniería, Investigación y Desarrollo, 8(1), 42-50.

Barber, A.; Tjokrosapoetro, S.; Charlton, T. (1986). Mud volcanoes, shale diapirs, wrench faults, and melanges in accretionary complexes, eastern Indonesia. AAPG Bulletin, 70(11), 1729-1741.

Barrero, D.; Pardo, A.; Vargas, C.A.; Martínez, J.F. (2015). Colombian sedimentary basins: nomenclature, boundaries and petroleum geology, new proposal. Agencia Nacional de Hidrocarburos.

Barton, D.C. (1933). Mechanics of formation of salt domes with special reference to Gulf coast salt domes of Texas and Louisiana. AAPG Bulletin, 17(9), 10251083. https://doi.org/10.1306/3D932B9C-16B111D7-8645000102C1865D

Bernal-Olaya, R.; Sánchez, J.; Mann, P.; Murphy, M. (2015a). Along-strike crustal thickness variations of the subducting Caribbean Plate produces two distinctive styles of thrusting in the offshore South Caribbean Deformed Belt, Colombia. In: C. Bartolini, P. Mann (eds.). Petroleum geology and potential of the Colombian Caribbean Margin (pp. 295-322). AAPG, Memoir 108. https://doi. org/10.1306/13531941M1083645

Bernal-Olaya, R.; Mann, P.; Vargas, C.A. (2015b). Earthquake, tomographic, seismic reflection, and gravity evidence for a shallowly dipping subduction zone beneath the Caribbean margin of northwestern Colombia. In: C. Bartolini, P. Mann (eds.). Petroleum geology and potential of the Colombian Caribbean Margin (pp. 247-270). AAPG, Memoir 108. https://doi. org/10.1306/13531939M1083642
Beeunas, M.A.; Schoell, M.; Beroiz, C. (1991). Geochemistry of natural gases from mud volcanoes and surface gas seeps in NW Colombia. AAPG Annual Convention Dallas, Texas.

Bezada, M.J.; Levander, A.; Schmandt, B. (2010). Subduction in the southern Caribbean: images from finite-frequency $\mathrm{P}$ wave tomography. Journal of Geophysical Research: Solid Earth, 115(B12). https://doi.org/10.1029/2010JB007682

Bishop, R.S. (1978). Mechanism for emplacement of piercement diapirs. AAPG Bulletin, 62(9), 15611583. https://doi.org/10.1306/C1EA5251-16C911D7-8645000102C1865D

Bloch, S.; Lander, R.H.; Bonnell, L. (2002). Anomalously high porosity and permeability in deeply buried sandstone reservoirs: Origin and predictability. AAPG Bulletin, 86(2), 301-328. https://doi.org/10.1306/61EEDABC-173E-11D78645000102C1865D

Bonini, M.; Rudolph, M.L.; Manga, M. (2016). Long- and short-term triggering and modulation of mud volcano eruptions by earthquakes. Tectonophysics, 672-673, 190-211. https://doi. org/10.1016/j.tecto.2016.01.037

Bowland, C.L. (1993). Depositional history of the western Colombian Basin, Caribbean Sea, revealed by seismic stratigraphy. GSA Bulletin, 105(10), 1321-1345. https://doi.org/10.1130/00167606(1993)105<1321:DHOTWC $>2.3 . C O ; 2$

Braunstein, G.; O’Brien, G.D. (1968). Diapirism and diapirs. American Association of Petroleum Geologists.

Briceño, L.A.; Vernette, G. (1992). Manifestaciones del diapirismo arcilloso en el margen colombiano del caribe. Earth Sciences Research Journal, 1, 21-30.

Brown, K.M. (1990). The nature and hydrogeologic significance of mud diapirs and diatremes for accretionary systems. Journal of Geophysical Research: Solid Earth, 95(B6), 8969-8982. https://doi.org/10.1029/JB095iB06p08969

Burel, T. (1982). Caractérisation des modalités d'évolution récente de la marge continentale Nord-Colombienne. Bulletin Institute Géologique du Bassin d'Aquitaine (Bordeaux) 21, 161-166. 
Bürgl, H. (1965). El límite oligo-mioceno en el terciario marino de Colombia. Revista de la Academia Colombiana de Ciencias Exactas, Físicas y Naturales, 12(47), 245-258.

Cadavid, T.; Rico, A. (1992). Amenazas geológicas por volcanismo de lodos para las áreas de Arroyo de Piedra y Galerazamba, departamento de Bolívar. Tesis, Universidad Nacional de Colombia, Medellín.

Carvajal, J.H.; Mendivelso, D.; Forero, H.; Castiblanco, C.R.; Pinzón, L.M.; Prada, M. (2010). Investigación del diapirismo de lodo y evolución costera del Caribe Colombiano. Geomorfología Sector 1. República de Colombia Ministerio de Minas y Energía, Instituto Colombiano de Geología y Minería, Bogotá.

Carvajal, J.H. (2016). Mud diapirism in the Central Colombian Caribbean Coastal Zone. In: M. Hermelin (ed.). Landscapes and Landforms of Colombia (pp. 35-53). Springer. https://doi. org/10.1007/978-3-319-11800-0_3

Carvajal, J.H.; Mendivelso, D. (2017). Volcanismo de lodo del Caribe central colombiano. Servicio Geológico Colombiano.

Castrec-Rouelle, M.; Bourles, D.L.; Boulegue, J.; Dia, A.N. (2002). Beryllium geochemistry constraints on the hydraulic behavior of mud volcanoes: The Trinidad Island case. Earth and Planetary Science Letters, 203(3-4), 957-966. https://doi. org/10.1016/S0012-821X(02)00922-6

Cediel, F.; Shaw, R.P.; Cáceres, C. (2003). Tectonic assembly of the Northern Andean Block. In: C. Bartolini, R.T. Buffler, J. Blickwede (eds.). The Circum-Gulf of Mexico and the Caribbean. Hydrocarbon Habitats, Basin Formation, and Plate Tectonics (pp. 815-848). AAPG, Memoir 79. https://doi.org/10.1306/M79877C37

Cerón, J.F.; Kellogg, J.N.; Ojeda, G.Y. (2007). Basement configuration of the northwestern South America - Caribbean Margin from recent geophysical data. CT\&F, Ciencia, Tecnología y Futuro, 3(3), 25-49.

Chamley, H. (1989). Clay sedimentology. SpringerVerlag.
Chiarabba, C.; De Gori, P.; Faccenna, C.; Speranza, F.; Seccia, D.; Dionicio, V.; Prieto, G.A. (2016). Subduction system and flat slab beneath the Eastern Cordillera of Colombia. Geochemistry, Geophysics, Geosystems, 17(1), 16-27. https:// doi.org/10.1002/2015GC006048

Cita, M.B.; Ivanov, M.K.; Woodside, J.M. (1996). The Mediterranean Ridge diapiric belt. Marine Geology, 132(1-4), 1-6.

Cobbold, P.; Rossello, E.; Vendeville, B. (1989). Some experiments on interacting sedimentation and deformation above salt horizons. Bulletin de la Société de Géologique de France, 5(3), 453-460. https://doi.org/10.2113/gssgfbull.V.3.453

Cobbold, P.R.; Rossello, E.A.; Roperch, P.; Arriagada, C.; Gómez, L.A.; Lima, C.C. (2007). Distribution, timing, and causes of Andean deformation across South America. Geological Society, London, Special Publications, 272, 321-343. https://doi. org/10.1144/GSL.SP.2007.272.01.17

Cohen, H.A.; McClay, K. (1996). Sedimentation and shale tectonics of the northern Niger Delta front. Marine and Petroleum Geology, 13(3), 313-328. https://doi.org/10.1016/0264-8172(95)00067-4

Correa, I.D. (1998). Amenazas geológicas asociadas al fenómeno del diapirismo de lodos, referencia Urbanización El Rodeo. Concepto técnico para Cardique. Informe inédito, 13 pp., Cartagena de Indias.

Correa, I.; Ríos, A.; González, G.; Toro, M.; Ojeda, G.; Restrepo, I. (2007). Erosión litoral entre Arboletes y Punta San Bernardo, costa caribe colombiana. Boletín de Geología, 29(2), 115-129.

Davies, R.J.; Stewart, S.A. (2005). Emplacement of giant mud volcanoes in the South Caspian Basin: 3D seismic reflection imaging of their root zones. Journal of the Geological Society, 162(1), 1-4. https://doi. org/10.1144/0016-764904-082

Davies, R.J.; Swarbrick, R.E.; Evans, R.J.; Huuse, M. (2007). Birth of a mud volcano: East Java, 29 May 2006. GSA Today, 17, 4-9.

Davies, R.J.; Brumm, M.; Manga, M.; Rubiandini, R.; Swarbrick, R.; Tingay, M. (2008). The East Java mud volcano (2006 to present): an earthquake or 
drilling trigger? Earth and Planetary Science Letters, 272(3-4), 627-638. https://doi.org/10.1016/j. epsl.2008.05.029

Davison, I.; Insey, M.; Harper, M.; Weston, P.; Blundell, D.; McClay, K.; Qualington, A. (1993). Physical modelling of overburden deformation around salt diapirs. Tectonophysics, 228(3-4), 255-274. https:// doi.org/10.1016/0040-1951(93)90344-J

Deville, E.; Guerlais, S.H.; Callec, Y.; Griboulard, R.; Huyghe, P.; Lallemant, S.; Mascle, A.; Noble, M.; Schmitz, J. (2006). Liquefied vs stratified sediment mobilization processes: insight from the South of the Barbados accretionary prism. Tectonophysics, 428(1-4), 33-47. https://doi. org/10.1016/j.tecto.2006.08.011

Deville, E.; Guerlais, S.H. (2009). Cyclic activity of mud volcanoes: evidences from Trinidad (SE Caribbean). Marine and Petroleum Geology, 26(9), 1681-1691. https://doi.org/10.1016/j. marpetgeo.2009.03.002

Dia, A.N.; Castrec-Rouelle, M.; Boulegue, J.; Comeau, P. (1999). Trinidad mud volcanoes: where do the expelled fluids come from? Geochimica et Cosmochimica Acta, 63(7-8), 1023-1038. https:// doi.org/10.1016/S0016-7037(98)00309-3

Dimitrov, L.I. (2002). Mud volcanoes - the most important pathway for degassing deeply buried sediments. Earth-Science Reviews, 59(1-4), 49-76. https://doi.org/10.1016/S0012-8252(02)00069-7

Duque-Caro, H. (1984a). Structural style, diapirism, and accretionary episodes of the Sinú-San Jacinto Terrane, southwestern Caribbean borderland. In: W.E. Bonini; R.B. Hargraves; R. Shagam (eds.). The Caribbean-South American plate boundary and regional tectonics. (pp. 303-316). Vol. 162, Geological Society of America. https://doi. org/10.1130/MEM162-p303

Duque-Caro, H. (1984b). Estilo estructural, diapirismo y episodios de acrecimiento del terreno Sinú-San Jacinto en el noroccidente de Colombia. Boletín Geológico, 27(2), 1-29.

Duque-Caro, H. (1990). Neogene stratigraphy, paleoceanography and paleobiogeography in northwest South America and the evolution of the Panama Seaway. Palaeogeography,
Paleoclimatology, Palaeoecology, 77(34), 203-234. https://doi.org/10.1016/00310182(90)90178-A

Dupré, S.; Buffet, G.; Mascle, J., Foucher, J.P.; Gauger, S.; Boetius, A.; Marfia, C. (2008). Highresolution mapping of large gas emitting mud volcanoes on the Egyptian continental margin (Nile Deep Sea Fan) by AUV surveys. Marine Geophysical Researches, 29(4), 275-290. https:// doi.org/10.1007/s11001-009-9063-3

Ercilla, G.; Alonso, B.; Estrada, F.; Chiocci, F.L.; Baraza, J.; Farran, M. (2002). The Magdalena Turbidite System (Caribbean Sea): presentday morphology and architecture model. Marine Geology, 185(3-4), 303-318. https://doi. org/10.1016/S0025-3227(02)00182-2

Etiope, G.; Milkov, A. (2004). A new estimate of global methane flux from onshore and shallow submarine mud volcanoes to the atmosphere. Environmental Geology, 46(8), 997-1002. https:// doi.org/10.1007/s00254-004-1085-1

Etiope, G.; Feyzullayev, A.; Milkov, A.V.; Waseda, A.; Mizobe, K.; Sun, C.H. (2009). Evidence of subsurface anaerobic biodegradation of hydrocarbons and potential secondary methanogenesis in terrestrial mud volcanoes. Marine and Petroleum Geology, 26(9), 1692-1703. https://doi.org/10.1016/j.marpetgeo.2008.12.002

Flinch, J.F. (2003). Structural evolution of the SinuLower Magdalena area (Northern Colombia). In: C. Bartolini, R. Buffler, J. Blickwede, J. (eds.). The Circum-Gulf of Mexico and the Caribbean: Hydrocarbon habitats, basin formation, and plate tectonics (pp. 776-796). AAPG Memoir 79.

Foucher, J.P.; Dupré, S.; Scalabrin, C.; Feseker, T.; Harmegnies, F.; Nouzé, H. (2010). Changes in seabed morphology, mud temperature and free gas venting at the Hakon Mosby Mud volcano, offshore Northern Norway, over the time period 2003-2006. Geo Marine Letters, 30(3-4), 157167. https://doi.org/10.1007/s00367-010-0193-z

García-Cortés, C.; Trejos-Tamayo, R.; VallejoHincapié, F.; Pardo-Trujillo, A. (2008). Planktonic foraminifera from mud volcanoes of the Sinú-San Jacinto basin. ACGGP Technical Committee, 3pp. 
García-González, M.; Bernal-Olaya, R.; FuentesLorenzo, J.L.; García-Ceballos, A.M. (2019). Mud diapirs and mud volcanoes associated with gas hydrates system in the Sinu Fold Belt of Colombia, South Western Caribbean and its significant in the petroleum system. AAPG Asia Pacific Region Geosciences Technology Workshop. Auckland.

Gardner, J. (2001). Mud volcanoes revealed and sampled on the Western Moroccan continental margin. Geophysical Research Letters, 28(2), 339-342. https://doi.org/10.1029/2000GL012141

Goad, S.T. (1816). Miscellaneous observations on the volcanic eruptions at the islands of Java and Sumbawa, with a particular account of the mud volcano at Grobogan. Journal Science Arts, 1, 245-258.

Gómez, A.; Martínez, J.I.; Yokoyama, Y. (2005). El Holoceno tardío en la región de Cartagena: reconstrucción paleoambiental de las terrazas marinas bajas. $X$ Congreso Colombiano de Geología, Bogotá.

Gracia, A.; Rangel-Buitrago, N.; Sellanes, J. (2012). Methane seep molluscs from the Sinú -San Jacinto fold belt in the Caribbean Sea of Colombia. Journal of the Marine Biological Association of the United Kingdom, 92(6), 1367-1377. https:// doi.org/10.1017/S0025315411001421

Graham, R.; Pepper, A. (2008). Observations on structures associated with mud diapirism and their role in petroleum charging and trapping. AAPG International Conference and Exhibition, Cape Town, South Africa.

González-Morales, O.; Rodríguez-Madrid, A.L.; Ríos-Reyes, C.A.; Ojeda-Bueno, G.Y. (2015). Relationship between the mud organic matter content and the maximum height of diapiric domes using analog models. CT\&F Ciencia, Tecnología y Futuro, 6(2), 17-32.

Graue, K. (2000). Mud volcanoes in deepwater Nigeria. Marine and Petroleum Geology, 17(8), 959-974. https://doi.org/10.1016/S0264-8172(00)00016-7

Guzmán, G.; Gómez, E.; Serrano, B. (2004). Geología de los cinturones del Sinú, San Jacinto y borde occidental del Valle Inferior del Magdalena,
Caribe Colombiano. Memoria Técnica INGEOMINAS. 134pp. Bogotá.

Hedberg, H.D. (1974). Relation of methane generation to undercompacted shales, shale diapirs and mud volcanoes. AAPG Bulletin, 58(4), 661-673. https://doi.org/10.1306/83D91466-16C7-11D78645000102C1865D

Herrera-Atencio, C.; Díaz-Mendoza, C. (2018). Evaluación geológica, geotécnica y ambiental de los fenómenos de volcanismo de lodos en la costa Caribe colombiana. Scientia et Technica, 23(1), 108-115.

Higgins, G.E.; Saunders, J.B. (1974). Mud volcanoes. Their nature and origin. In: P. Jung, H. Bolli, R. Panchaud, J. Saunders, H. Schaefer, F. Wiedenmayer (eds.). Contributions to the Geology and Paleobiology of the Caribbean and adjacent areas (pp. 101-152). Verhandlungen Naturforschenden Gesselschaft in Basel 84.

Higgs, H. (2009). Caribbean-South America oblique collision model revised. Geological Society, London, Special Publications, 328, 613-657. https://doi.org/10.1144/SP328.25

Horton, B.K. (2018). Sedimentary record of Andean mountain building. Earth-Science Reviews, 178, 279-309. https://doi.org/10.1016/j. earscirev.2017.11.025

Hovland, M.; Hill, A.; Stokes, D. (1997). The structure and geomorphology of the Dashgil mud volcano, Azerbaijan. Geomorphology, 21(1), 1-15. https:// doi.org/10.1016/S0169-555X(97)00034-2

Istadi, B.; Pramono, G.H.; Sumintadireja, P.; Alam, S. (2009). Modeling study of growth and potential geohazard for LUSI mud volcano: East Java, Indonesia. Marine and Petroleum Geology, 26(9), 1724-1739. https://doi.org/10.1016/j. marpetgeo.2009.03.006

Istadi, B.P.; Wibowo, H.T.; Sunardi, S.; Hadi, E.; Sawolo, N. (2012). Mud volcano and its evolution. In: I.A. Dar (ed.). Earth Sciences (pp. 375-434). InTech. https://doi.org/10.5772/24944

Ivanov, M.K.; Limonov, A.F.; van Weering, T.C. (1996). Comparative characteristics of the Black Sea and Mediterranean Ridge mud volcanoes. 
Marine Geology, 132(1-4), 253-271. https://doi. org/10.1016/0025-3227(96)00165-X

Jackson, M.P.A.; Talbot, C.J. (1986). External shapes, strain rates and dynamics of salt structures. GSA Bulletin, 97(3), 305-323. https://doi. org/10.1130/0016-7606(1986)97<305:ESSRAD> 2.0.CO;2

Jackson, M.P.A.; Cornelius, R.R.; Craig, C.R.; Gansser, A.; Stöcklin, J.; Talbot, C.J. (1990). Salt diapirs of the Great Kavir, central Iran. Vol. 177. GSA.

Jackson,M.P.A.; Vendeville,B.C.(1994). Regionalextension as a geologic trigger for diapirism. GSA Bulletin, 106(1), 57-73. https://doi.org/10.1130/00167606(1994)106<0057:REAAGT>2.3.CO;2

Jackson, M.P.A.; Vendeville, B.C.; Schultz-Ela, D.D. (1994). Structural dynamics of salt systems. Annual Review of Earth and Planetary Sciences, 22, 93-117. https://doi.org/10.1146/annurev. ea.22.050194.000521

James, K.H. (2006). Arguments for and against the Pacific origin of the Caribbean Plate: discussion, finding for an inter-American origin. Geologica Acta, 4(1-2), 279-302. https://doi. org/10.1344/105.000000370

James, K.H. (2009). In situ origin of the Caribbean: discussion of data. Geological Society, London, Special Publications, 328, 77-125. https://doi. org/10.1144/SP328.3

James, K.H. (2010). In situ Caribbean - the data. In: James, K.H.; Lorente, M.A.; Pindell, J. (eds.). Geology of the area between North and South America, with focus on the origin of the Caribbean plate. Geological Society of America.

Kellogg, J.N.; Franco-Camelio, G.B.; Mora-Páez, H. (2019). Cenozoic tectonic evolution of the North Andes with constraints from volcanic ages, seismic reflection, and satellite geodesy. In: B.K. Horton, A. Folguera (eds.). Andean Tectonics (pp. 69-102). Chapter 4. Elsevier. https://doi. org/10.1016/B978-0-12-816009-1.00006-X

Kerr, P.F.; Drew, I.M.; Richardson, D.S. (1970). Mud volcano clay, Trinidad, West Indies. AAPG Bulletin, 54(11), 2101-2110. https://
doi.org/10.1306/5D25CC71-16C1-11D78645000102C1865D

Kerr, A.; Tarney, J. (2005). Tectonic evolution of the Caribbean and northwestern South America: The case for accretion of two Late Cretaceous oceanic plateaus. Geology, 33(4), 269-272. https://doi. org/10.1130/G21109.1

Kholodov, V.N. (1983). Postsedimentary transformations in elisional basins (example from Eastern Pre-Caucasus) (in Russian).

Kopf, A.J. (2002). Significance of mud volcanism. Reviews of Geophysics, 40(2), 1-52. https://doi. org/10.1029/2000RG000093

Kopf, A.J. (2003). Global methane emission through mud volcanoes and its past and present impact on the Earth's climate. International Journal of Earth Sciences, 92(5), 806-816. https://doi.org/10.1007/ s00531-003-0341-z

Ladd, J.W.; Truchan, M.; Talwani, M.; Stoffa, P.L.; Buhl, P.; Houtz, R.; Mauffret, A.; Westbrook, G.K. (1984). Seismic reflection profiles across the southern margin of the Caribbean. In: W.E. Bonini, R.B. Hargraves, R. Shagam (eds.). The Caribbean-South American plate boundary and regional tectonics (pp. 153-159). GSA. https:// doi.org/10.1130/MEM162-p153

Limonov, A.; van Weering, T.C.; Kenyon, N.; Ivanov, M.; Meisner, L. (1997). Seabed morphology and gas venting in the Black Sea mud volcano area: observations with the MAK-1 deep-tow sidescan sonar and bottom profiler. Marine Geology, 137(1-2), 121-136. https://doi.org/10.1016/ S0025-3227(96)00083-7

Link, W.K. (1952). Significance of oil and gas seeps in world oil exploration. AAPG Bulletin, 36(8), 15051540. https://doi.org/10.1306/5CEADB3F-16BB11D7-8645000102C1865D

Lozano, E.; Zamora, N. (2014). Compilación de las cuencas de Sinú - San Jacinto. Servicio Geológico Colombiano, Tectónica, Geociencias Básicas, Bogotá.

MacDonald, I.R.; Buthman, D.B.; Sager, W.W.; Peccini, M.B.; Guinasso, N.L. (2000). Pulsed 
oil discharge from mud volcano. Geology, 28(10), 907-910. https://doi.org/10.1130/00917613(2000)28<907:PODFAM $>2.0 . \mathrm{CO} ; 2$

Mantilla-Pimiento, A.M. (2007). Crustal structure of the SW Colombian Caribbean Margin: Geological interpretation of geophysical data. Ph.D. Thesis, Friedrich-Schiller Universität Jena.

Manga, M.; Brodsky, E. (2006). Seismic triggering of eruptions in the far field: volcanoes and geysers. Annual Review of Earth Planetary Sciences, 34, 263-291. https://doi.org/10.1146/annurev. earth.34.031405.125125

Manga, M.; Brumm, M.; Rudolph, M.L. (2009). Earthquake triggering of mud volcanoes. Marine and Petroleum Geology, 26(9), 1785-1798. https://doi.org/10.1016/j.marpetgeo.2009.01.019

Marín, J.P.; Bermúdez, H.D.; Aguilera, R.; Jaramillo, J.M.; Rodríguez, J.V.; Ruiz, E.C.; Cerón, M.R. (2010). Evaluación geológica y prospectividad sector Sinú - Urabá. Boletín de Geología, 32(1), 145-153.

Martínez, J.M.; Parra, E.; Paris, G.; Forero, C.; Bustamante, M.; Cardona, O.; Jaramillo, J.P. (1994). Los sismos del Atrato Medio 17 y 18 de octubre de 1992, Noroccidente de Colombia. Revista Ingeominas, 4, 35-76.

Mazzini, A.; Svensen, H.; Planke, S.; Guliyev, I.; Akhmanov, G.G.; Fallik, T.; Banks, D. (2009). When mud volcanoes sleep: Insight from seep geochemistry at the Dashgil mud volcano, Azerbaijan. Marine and Petroleum Geology, 26(9), 1704-1715. https://doi.org/10.1016/j. marpetgeo.2008.11.003

Medwedeff, D.A. (1989). Growth fault-bend folding at southeast Lost Hills, San Joaquin Valley, California. AAPG Bulletin, 73(1), 54-67. https:// doi.org/10.1306/703C9AE6-1707-11D78645000102C1865D

Mellors, R.; Kilb, D.; Aliyev, A.; Gasanov, A.; Yetirmishli, G. (2007). Correlations between earthquakes and large mud volcano eruptions. Journal of Geophysical Research: Solid Earth, 112(B4). https://doi.org/10.1029/2006JB004489
Milkov, A.V. (2000). Worldwide distribution of submarine mud volcanoes and associated gas hydrates. Marine Geology, 167(1-2), 29-42. https:// doi.org/10.1016/S0025-3227(00)00022-0

Milkov, A.V. (2005). Global distribution of mud volcanoes and their significance in petroleum exploration as a source of methane in the atmosphere and hydrosphere and as geohazard. In: G. Martinelli, B. Panahi (eds.). Mud Volcanoes, Geodynamics and Seismicity (pp. 29-34). Springer. https://doi.org/10.1007/1-4020-3204-8_3

Mora, C. (2018). Evaluación de rocas generadoras en las cuencas Sinú-San Jacinto y Valle Inferior del Magdalena y su relación con la prospectividad y el modelo de sistemas petrolíferos. Universidad de Caldas, Instituto de Investigaciones en Estratigrafía.

Mora, J.A.; Oncken, O.; Le Breton, E.; Mora, A.; Veloza, G.; Vélez, V.; de Freitas, M. (2018). Controls on forearc basin formation and evolution: insights from Oligocene to Recent tectonostratigraphy of the Lower Magdalena Valley basin of northwest Colombia. Marine and Petroleum Geology, 97, 288-310. https://doi.org/10.1016/j. marpetgeo.2018.06.032

Mora-Páez, H.; Kellogg, J.; Freymueller, J.; Mencin, D.; Fernandes, R.M.; Diederix, H.; LaFemina, P.; Cardona-Piedrahíta, L.; Lizarazo, S.; PeláezGaviria, J.R.; Díaz-Mila, F.; Bohórquez-Orozco, O.P.; Giraldo-Londoño, L.; Corchuelo-Cuervo, Y. (2019). Crustal deformation in the northern Andes - A new GPS velocity field. Journal of South American Earth Sciences, 89, 76-91. https://doi. org/10.1016/j.jsames.2018.11.002

Morales-Giraldo, D.F.; Rocha-Gutiérrez, V.L.; PosadaPosada, B.O. (2017). Geomorfología de los fondos submarinos del Parque Nacional Natural Corales de Profundidad, mar Caribe colombiano. Boletín de Investigaciones Marinas y Costeras, 46(2), 73-90. https://doi.org/10.25268/bimc. invemar.2017.46.2.727

Morley, C.K. (2003). Outcrop examples of mudstone intrusions from the Jerudong anticline Brunei Darussalam and inferences for hydrocarbon reservoirs. Geological Society, London, Special Publications, 216, 381-394. https://doi. org/10.1144/GSL.SP.2003.216.01.25 
Mourad, B. (2005). New seismic Neogene clay diapirs and hydrocarbon implications in the North-Eastern African margin of Tunisia. In: G. Martinelli, B. Panahi (eds.). Mud volcanoes, geodynamics and seismicity (pp. 1-15). Chapter 1. Springer-Verlag. https://doi.org/10.1007/1-4020-3204-8_1

Musgrave, A.W.; Hicks, W.G. (1968). Outlining shale masses by geophysical methods. In: J. Braunstein; G.D. O'Brien (eds.). Diapirism and diapirs: $a$ symposium. Vol. 8. AAPG. https://doi.org/10.1306/ M8361C8

Nettleton, L.L. (1934). Fluid mechanics of salt domes. AAPG Bulletin, 18(9), 1175-1204. https:// doi.org/10.1306/3D932C74-16B1-11D78645000102C1865D

Nettleton, L.L.; Elkins, T.A. (1947). Geological materials made from granular materials. EOS, Transactions American Geophysical Union, 28(3), 451-466. https://doi.org/10.1029/TR028i003p00451

Niemann, H.; Lösekann, T.; de Beer, D.; Elvert, M.; Nadalig, T.; Knittel, K.; Amann, R.; Sauter, E.J.; Schlüter, M.; Klages, M.; Foucher, J.P.; Boetius, A. (2006). Novel microbial communities of the Haakon Mosby mud volcano and their role as a methane sink. Nature, 443, 854-858. https://doi. org/10.1038/nature05227

Niemann, H.; Boetius, A. (2010). Mud volcanoes. In: K.N. Timmis (ed.). Handbook of hydrocarbon and lipid microbiology (pp. 205-214). Springer. https://doi.org/10.1007/978-3-540-77587-4_13

Nordgard-Bolas, H.M.; Hermanrud, C.; Teige, G.M.G. (2004). Origin of overpressures in shales: constraints from basin modeling. AAPG Bulletin, 88(2), 193-211. https://doi. org/10.1306/10060302042

Ojeda, G.Y.; Restrepo, I.C.; Correa, I.D.; Ríos, A.A. (2007). Morfología y arquitectura interna de una plataforma continental cambiante: Golfo de Morrosquillo. Boletín de Geología, 29(2), 105114.

Oppenheim, V. (1957). Petroleum Geology of the Sinu Basin, Colombia. XX International Geological Congress, México.
Pérez, O.J.; Wesnousky, S.G.; De La Rosa, R.; Márquez, J.; Uzcátegui, R.; Quintero, C.; Liberal, L.; MoraPáez, H.; Szeliga, W. (2018). On the interaction of the North Andes plate with the Caribbean and South American plates in northwestern South America from GPS geodesy and seismic data. Geophysical Journal International, 214(3), 19862001. https://doi.org/10.1093/gji/ggy230

Pettijohn, F.J. (1975). Sedimentary rocks. 3rd ed. Harper \& Row Publishers.

Pindell, J.; Kennan, L.; Maresch, W.V.; Stanek, K.P.; Draper, G.; Higgs, R. (2005). Plate-kinematics and crustal dynamics of circum-Caribbean arccontinent: Tectonic controls on basin development in Proto-Caribbean margins. In: H.G. Lallemant, V.B. Sisson (eds.). Caribbean-South American plate interactions, Venezuela (pp. 7-52). GSA. https://doi.org/10.1130/0-8137-2394-9.7

Pindell, J.L.; Kennan, L. (2009). Tectonic evolution of the Gulf of Mexico, Caribbean and northern South America in the mantle reference frame: an update. Geological Society, London, Special Publications, 328, 1-55. https://doi.org/10.1144/ SP328.1

Planke, S.; Svensen, H.; Hovland, M.; Banks, D.; Jamtveit, B. (2003). Mud and fluid migration in active mud volcanoes in Azerbaijan. GeoMarine Letters, 23(3-4), 258-268. https://doi. org/10.1007/s00367-003-0152-z

Podladchikov, Y.; Talbot, C.; Poliakov, A.N.B. (1993). Numerical models of complex diapirs. Tectonophysics, 228(3-4), 189-198. https://doi. org/10.1016/0040-1951(93)90340-P

Potter, P.E.; Maynard, J.B.; Pryor, W.A. (1980). Sedimentology of shale. Springer-Verlag.

Quintero-Ramírez, J.D. (2012). Interpretación sísmica de volcanes de lodo en la zona occidental del abanico del delta del río Magdalena, Caribe Colombiano. Tesis, Universidad EAFIT, Medellín, Colombia.

Reed, D.L.; Silver, E.A.; Tagudin, J.E.; Shipley, T.H.; Vrolijk, P. (1990). Relations between mud volcanoes, thrust deformation, slope sedimentation, and gas hydrate, offshore north 
Panama. Marine and Petroleum Geology, 7(1), 44-54. https://doi.org/10.1016/02648172(90)90055-L

Restrepo, I.C.; Ojeda, G.Y.; Correa, I.D. (2007). Geomorfología de la plataforma somera del departamento de Córdoba, costa caribe colombiana. Boletín de Ciencias de la Tierra, 20, 39-52.

Rodríguez, I.; Bulnes, M.; Poblet, J.; Masini, M.; Flinch, J. (2021). Structural style and evolution of the offshore portion of the Sinu Fold Belt (South Caribbean Deformed Belt) and adjacent part of the Colombian Basin. Marine and Petroleum Geology, $125 . \quad$ https://doi.org/10.1016/j. marpetgeo.2020.104862

Rossello, E.A.; Rey, A.; Ramírez, V. (2011). Segmentación tectonosedimentaria del margen pasivo caribeño colombiano. XVIII Congreso Geológico Argentino, Neuquén, Argentina.

Rossello, E.A.; Cossey, S.P.J. (2012). What is the evidence for subduction in the Caribbean margin of Colombia? XI Simposio Bolivariano de cuencas Subandinas, Cartagena, Colombia.

Rossello, E.A.; Osorio, J.A. (2016). Influencia del cinturón del Sinú-San Jacinto en la distribución 4D del diapirismo argilocinético del Margen Caribeño Colombiano. XII Simposio Bolivariano de Cuencas Subandinas, Bogotá, Colombia.

Rossello, E.A. (2018). Influencia del soterramiento en la calidad de los reservorios de hidrocarburos: fundamentos, metodologías prácticas de reconocimiento e interpretación. Revista de la Asociación Geológica Argentina, 75(2), 722-735.

Sawolo, N.; Sutriono, E.; Istadi, B.P.; Darmoyo, A.B. (2009). The LUSI mud volcano triggering controversy: was it caused by drilling? Marine and Petroleum Geology, 26, 1766-1784. https:// doi.org/10.1016/j.marpetgeo.2009.04.002

Sawolo, N.; Sutriono, E.; Istadi, B.P.; Darmoyo, A.B. (2010). Was LUSI caused by drilling? - Authors reply to discussion. Marine and Petroleum Geology, 27, 1658-1675. https://doi. org/10.1016/j.marpetgeo.2010.01.018
Schamel, S.; Allen, R.B.; Schelling, D.; Wavrek, D.; Laverde, F.; Ballesteros, C.I. (1998). Hydrocarbon potential of the Sinú-San Jacinto region of Northern Colombia. Annual Convention Abstract, Salt Lake City, USA.

Schultz-Ela, D.D.; Jackson, M.P.A.; Vendeville, B.C. (1993). Mechanics of active salt diapirism. Tectonophysics, 228(3-4), 275-312. https://doi. org/10.1016/0040-1951(93)90345-K

Shepard, F.P.; Dill, R.F.; Heezen, B.C. (1968). Diapiric intrusions in foreset slope sediments off Magdalena Delta, Colombia. AAPG Bulletin, 52(11), 21972207. https://doi.org/10.1306/5D25C55F-16C111D7-8645000102C1865D

Shipley, T.; Houston, M.; Buffer, R.; Shaub, J.; McMillen, K.J.; Ladd, J.W.; Worzel, J.L. (1979). Seismic reflection evidence for the widespread occurrence of possible gas hydrate horizons on continental slopes and rises. AAPG Bulletin, 63(12), 2204-2213.

Somoza, L.; León, R.; Ivanov, M.; Fernández-Puga, M.; Gardner, J.; Hernández-Molina, J.; Pinheiro, L.; Rodero, J.; Lobato, A.; Maestro, A.; Vázquez, J.T.; Medialdea, T.; Fernández-Salas, L.M. (2003). Seabed morphology and hydrocarbon seepage in the Gulf of Cadiz mud volcano area: Acoustic imagery, multibean and ultra-high-resolution seismic data. Marine Geology, 195(1-4), 153-176. https://doi.org/10.1016/S0025-3227(02)00686-2

Stainforth, R.M. (1969). The concept of sea-floor spreading applied to Venezuela. Asociación Venezolana de Geología, Minería y Petróleo, Boletín Informático, 12, 257-274.

Stern, R.J. (1998). A subduction primer for instructors of introductory geology courses and authors of introductory geology textbooks. Journal of Geoscience Education, 46(3), 221-228. https:// doi.org/10.5408/1089-9995-46.3.221

Stern, R.J. (2002). Subduction zones. Reviews of Geophysics, 40(4). https://doi. org/10.1029/2001RG000108

Stewart, S.A.; Davies, R.J. (2006). Structure and emplacement of mud volcano systems in the South Caspian Basin. AAPG Bulletin, 90(5), 771786. https://doi.org/10.1306/11220505045 
Summer, R.H.; Westbrook, G.K. (2001). Mud diapirism in front of the Barbados accretionary wedge: the influence of fracture zones and North AmericaSouth America plate motions. Marine and Petroleum Geology, 18(5), 591-613. https://doi. org/10.1016/S0264-8172(01)00010-1

Taboada, A.; Rivera, L.A.; Fuenzalida, A.; Cisternas, A.; Philip, H.; Bijwaard, H.; Rivera, C. (2000). Geodynamics of the northern Andes: subductions and intracontinental deformation (Colombia). Tectonics, 19(5), 787-813. https://doi. org/10.1029/2000TC900004

Talbot, C.J.; Rönnlund, P.; Schmeling, H.; Koyi, H.; Jackson, M.P.A. (1991). Diapiric spoke patterns. Tectonophysics, 188(1-2), 187-201. https://doi. org/10.1016/0040-1951(91)90322-J

Talbot, C.J. (1992). Centrifuged models of Gulf of Mexico profile. Marine and Petroleum Geology, $9(4), \quad 412-432$. https://doi.org/10.1016/02648172(92)90052-G

Talbot, C.J. (1995). Molding of salt diapirs by stiff overburden. In: M.P.A. Jackson, D.G. Roberts, S. Snelson (eds.). Salt tectonics: a global perspective (pp.61-75). Vol. 65.AAPG. https://doi.org/10.1306/ M65604C4

Taylor, M.H.; Dillon, W.P.; Pecher, I.A. (2000). Trapping and migration of methane associated with the gas hydrate stability zone at the Blake Ridge Diapir: New insights from seismic data. Marine Geology, 164(1-2), 79-89. https://doi.org/10.1016/S00253227(99)00128-0

Tingay, M.; Heidbach, O.; Davies, R.; Swarbrick, R. (2008). Triggering of the Lusi mud eruption: Earthquake versus drilling initiation. Geology, 36(8), 639-642. https://doi.org/10.1130/G24697A.1

Tingay, M.; Manga, M.; Rudolph, M.L.; Davies, R. (2018). An alternative review of facts, coincidences and past and future studies of the Lusi eruption. Marine and Petroleum Geology, 95, 345-361 https://doi.org/20.1016/j.parpetgeo.2017.12.031

Tinivella, U.; Giustiniani, M. (2013). An overview of mud volcanoes associated to gas hydrate system. Updates in Volcanology - New Advances in understanding volcanic systems, 225-267. https:// doi.org/10.5772/51270
Toto, E.A.; Kellogg, J.N. (1992). Structure of the SinuSan Jacinto fold belt - an active accretionary prism in northern Colombia. Journal of South American Earth Sciences, 5(2), 221-222. https:// doi.org/10.1016/0895-9811(92)90039-2

Toussaint, J.F.; Restrepo, J.J. (2020). Tectonostratigraphic terranes in Colombia: An update. Second part: Oceanic terranes. In: J. Gómez, A.O. Pinilla-Pachon (eds.). The Geology of Colombia (pp. 239-277). Vol. 2. Servicio Geológico Colombiano. https://doi.org/10.32685/ pub.esp.36.2019.07

Uyeda, S. (1982). Subduction zones: An introduction to comparative subductology. Tectonophysics, 81(3-4), 133-159. https://doi.org/10.1016/00401951(82)90126-3

Van Rensbergen, P.; Morley, C.K.; Ang, D.W.; Hoan, T.Q.; Lam, N.T. (1999). Structural evolution of shale diapirs from reactive rise to mud volcanism: 3D seismic data from the Baram delta, offshore Brunei Darussalam. Journal of the Geological Society, 156(3), 633-650 https://doi.org/10.1144/ gsjgs.156.3.0633

Velázquez, A. (2005). Los terremotos del Atrato MedioMurindó en octubre de 1992. En: M. Hermelin (ed.). Desastres de origen natural en Colombia 1979-2004 (pp. 91-108). Fondo Editorial EAFIT.

Vendeville, B.C.; Jackson, M.P.A. (1992a). The rise of diapirs during thin-skinned extension. Marine and Petroleum Geology, 9(4), 331-353. https:// doi.org/10.1016/0264-8172(92)90047-I

Vendeville, B.C.; Jackson, M.P.A. (1992b). The fall of diapirs during thin-skinned extension. Marine and Petroleum Geology, 9(4), 354-371. https:// doi.org/10.1016/0264-8172(92)90048-J

Vernette, G. (1989). Examples of diapiric control on shelf topography and sedimentation patterns on the Colombian Caribbean continental shelf. Journal of South American Earth Sciences, 2(4), 391-400. https://doi.org/10.1016/08959811(89)90017-5

Vernette, G.; Mauffret, A.; Bobier, C.; Briceno, L.; Gayet, J. (1992). Mud diapirism, fan sedimentation and strike-slip faulting, Caribbean Colombian 
Margin. Tectonophysics, 202(2-4), 335-349. Weijermars, R.; Jackson, M.P.A.; Vendeville, B. (1993).

https://doi.org/10.1016/0040-1951(92)90118-P

Vinnels, J.S.; Butler, R.W.H.; McCaffrey, W.D.; Paton, D.A. (2010). Depositional processes across the Sinú accretionary prism, offshore Colombia. Marine and Petroleum Geology, 27(4), 794-809. https://doi.org/10.1016/j.marpetgeo.2009.12.008

Wagner-Friedrichs, M.; Krastel, S.; Spiess, V.; Ivanov, M.; Bohrmann, G.; Meisner, L. (2008). Three-dimensional seismic investigations of the Sevastopol mud volcano in correlation to gas/ fluid migration pathways and indications for gas hydrate occurrences in the Sorokin Trough (Black Sea). Geochemistry, Geophysics, Geosystems, 9(5). https://doi.org/10.1029/2007GC001685

Wiedicke, M.; Neben, S.; Spiess, V. (2001). Mud volcanoes at the front of the Makran accretionary complex, Pakistan. Marine Geology, 172(12), 57-73. https://doi.org/10.1016/S00253227(00)00127-4
Rheological and tectonic modelling of salt provinces. Tectonophysics, 217(1-2), 143-174. https://doi. org/10.1016/0040-1951(93)90208-2

Wu, T. (2005). Activity, mud migration, and formation mechanisms of Helgoland and Dvurechenskii mud volcanoes, Black Sea. PhD. Thesis, University Bremen.

Yassir, N.A. (1989). Mud volcanoes and the behavior of overpressured clays and silts. PhD. Thesis, University College London.

Zapata-García, G.; Rodríguez-García, G. (2020). New contributions to knowledge about the ChocóPanama Arc in Colombia, including a new segment south of Colombia. In: J. Gómez, D. MateusZabala (eds.). The Geology of Colombia (pp. 417450). Vol. 3. Servicio Geológico Colombiano. https://doi.org/10.32685/pub.esp.37.2019.14

Fecha de recibido: 27 de julio de 2021 Fecha de aprobado: 09 de noviembre de 2021 